\title{
A Conserved Helix in the C-Terminal Region of Watermelon Silver Mottle Virus Nonstructural Protein S Is Imperative For Protein Stability Affecting Self-Interaction, RNA Silencing Suppression, and Pathogenicity
}

\author{
Chung-Hao Huang, ${ }^{1,2}$ Mung-Hsia Foo, ${ }^{1}$ Joseph A. J. Raja, ${ }^{1,2}$ Yue-Rong Tan, ${ }^{1}$ Tzu-Tung Lin, ${ }^{1}$ \\ Shih-Shun Lin, ${ }^{2,3}$ and Shyi-Dong Yeh ${ }^{1,2,+}$ \\ ${ }^{1}$ Department of Plant Pathology, National Chung Hsing University, Taichung 40227, Taiwan, Republic of China \\ ${ }^{2}$ Advanced Plant Biotechnology Center, National Chung Hsing University \\ ${ }^{3}$ Institute of Biotechnology, National Taiwan University, Taipei 106, Taiwan, Republic of China
}

Accepted 8 January 2020.

\begin{abstract}
In orthotospovirus, the nonstructural protein $\mathrm{S}$ (NSs) is the RNA-silencing suppressor (RSS) and pathogenicity determinant. Here, we demonstrate that a putative $\alpha$-helix, designated H8, spanning amino acids 338 to 369 of the $C$-terminal region of the NSs protein, is crucial for self-interaction of watermelon silver mottle virus NSs protein and that the $\mathrm{H} 8$ affects RSS function. Co-immunoprecipitation, yeast two-hybrid, and bimolecular fluorescence complementation analyses revealed that the triple point mutation (TPM) of $\mathrm{H8}$ amino acids Y338A, $\mathrm{H350A}$, and F353A resulted in NSs protein self-interaction dysfunction. Transient expression of H8-deleted $(\Delta \mathrm{H8})$ and TPM NSs proteins in Nicotiana benthamiana plants by agroinfitration indicated that these proteins have weaker RSS activity and are far less stable than wild-type (WT) NSs. However, an electrophoretic mobility assay revealed that small interfering RNA (siRNA) binding ability of TPM NSs protein is not compromised. The pathogenicity assay of WT NSs protein expressed by the attenuated turnip mosaic virus vector restored severe symptoms in recombinant-infected $N$. benthamiana plants but not for $\Delta \mathrm{H8}$ or TPM proteins. Taken together, we conclude that the $\mathrm{H8}$ helix in the $\mathrm{C}$-terminal region of NSs protein is crucial for stabilizing NSs protein through self-interaction to maintain normal functions of RSS and pathogenicity, but not for NSssiRNA binding activity.
\end{abstract}

${ }^{\dagger}$ Corresponding author: S. D. Yeh; sdyeh@nchu.edu.tw

Funding: This work was supported by grants provided by the Ministry of Science and Technology, Taiwan, R.O.C. (NSC-101-2321-B-005-010, NSC-102-2321-B-005-006, MOST 103-2321-B-005-006, NSC-104-2911I-005-301, and NSC-105-2911-I-005-301). This work was also financially supported in part, within the framework of the Higher Education Sprout Project by the Ministry of Education (MOE) in Taiwan, R.O.C., by the Advanced Plant Biotechnology Center from The Featured Areas Research Center Program.

*The $\boldsymbol{e}$-Xtra logo stands for "electronic extra" and indicates that two supplementary figures are published online.

The author(s) declare no conflict of interest.

@) 2020 The American Phytopathological Society
RNA-silencing is an important defense mechanism in plants and is highly conserved in all kingdoms. During single stranded RNA virus infection, the double-stranded replicative form (dsRNA) that synthesized from viral messenger RNAs (mRNAs) by host RNA-dependent RNA polymerase 6 (RDR6) (Curaba and Chen 2008) and the cofactor suppressor gene silencing 3 (SGS3) (Fukunaga and Doudna 2009; Mourrain et al. 2000; Peragine et al. 2004) trigger the host RNA-silencing mechanism. These dsRNAs are digested by Dicer-like proteins (DCLs) to generate 21- to 24-nucleotide small interfering RNAs (siRNAs) (Xie et al. 2004), which are loaded into and unwound by the RNA-induced silencing complex (RISC) containing a key component, argonaute protein (AGO), that can guide the complementary strands of siRNAs to target the homologous RNA (Hutvagner and Simard 2008; Nykänen et al. 2001). Consequently, the RISC complex cleaves the targeted RNA or represses its translation to suppress gene expression (Collins and Cheng 2005).

To antagonize the RNA silencing, plant viruses have evolved RSS proteins for their establishment in host cells (Csorba et al. 2009; Ruiz-Ferrer and Voinnet 2009). Different suppressors inhibit RNA-silencing pathways differently by inhibiting DCL function (Haas et al. 2008; Takeda et al. 2005), binding to long dsRNAs or siRNAs (Lakatos et al. 2006; Mérai et al. 2006; Schnettler et al. 2010; Ye et al. 2003), intefering with RDR6 activity directly (Guo et al. 2013), interacting with SGS3 (Fukunaga and Doudna 2009), degrading (Csorba et al. 2010) or binding (Azevedo et al. 2010; Zhang et al. 2006) AGO1, or interacting with other host essential factors (Cañizares et al. 2013; Yang et al. 2011). Moreover, formation of homo-dimer or homo-oligomer of some suppressors are essential for certain functions, as exemplified by p19 of tombusvirus (Ye et al. 2003), 2b of cucumovirus (Xu et al. 2013), p38 of carmovirus (Azevedo et al. 2010), triple-gene block protein 1 (TGBp1) of potexvirus (Okano et al. 2014), cysteine-rich protein of furovirus (Sun et al. 2013), p21 of closterovirus (Ye and Patel 2005) P9-1 of fijivirus (Wu et al. 2013), and HC-Pro of potyvirus (Ruiz-Ferrer et al. 2005).

In general, viral suppressors are multiple-function proteins that inhibit host gene silencing at different steps in one or both the monomeric and oligomeric forms. The p19 protein, a wellstudied RNA-silencing suppressor (RSS), forms a tail-to-tail homo-dimer that binds siRNA duplexes to prevent siRNA loading into RISC (Ye et al. 2003). In potexviral TGBp1 (Valli 
et al. 2008), homo-oligomerization is required for the aggregation of SGS3/RDR6 bodies and RSS function (Okano et al. 2014). The B2 protein of alphanodavirus (Chao et al. 2005; Seo et al. 2012) and AL2 protein of begomovirus (Yang et al. 2007) have silencing suppression activity in both monomeric and dimeric forms. However, mutation of the charged amino acid (aa) residues at the $\mathrm{N}$-terminal region of the $\mathrm{B} 2$ protein of flock house virus resulted in self-interaction dysfunction that enhances the RNA-silencing suppression activity (Seo et al. 2012). On the other hand, tomato golden mosaic virus AL2 monomer alone is sufficient to suppress the local gene silencing (Yang et al. 2007).

The species of watermelon silver mottle virus (WSMoV) belongs to the genus Orthotospovirus of the family Tospoviridae (reported online by the International Committee on Taxonomy of Viruses). Orthotospoviruses have a tripartite RNA genome containing a negative-sense L-RNA $(9 \mathrm{~kb})$ that encodes a viral RNA-dependent RNA polymerase (Chu et al. 2001; de Haan et al. 1991), an ambisense M-RNA (4.8 kb) that encodes glycoprotein N (Gn), glycoprotein C (Gc), and nonstructural protein M (NSm) (Chu and Yeh 1998; Kormelink et al. 1994; Storms et al. 1995), and an ambisense S-RNA (3.5 kb) that encodes nucleocapsid protein (NP) and nonstructural protein S (NSs) (de Haan et al. 1992; Kormelink et al. 1991; Yeh and Chang 1995; Yeh et al. 1996). NSs protein is the RSS of orthotospovirus (Bucher et al. 2003; Garcia et al. 2006; Goswami et al. 2012; Reavy et al. 2004; Takeda et al. 2002), with multiple functions including: i) NTPase and $5^{\prime} \alpha$ phosphatase (Lokesh et al. 2010), ii) pathogenicity determinant (Goswami et al. 2012; Huang et al. 2015; Kormelink et al. 1991), iii) replication enhancer (Oliveira et al. 2011), iv) avirulence factor of the resistant $T s w$ gene in pepper (de Ronde et al. 2013), v) essential factor for persistent infection and transmission by thrips (Margaria et al. 2014), and vi) helicase activity (Bhushan et al. 2015).

Similar to potyviral suppressor HC-Pro (Lakatos et al. 2006; Mérai et al. 2006), orthotospoviral NSs protein binds to the duplexes of microRNA (miRNA), siRNA, and long dsRNA (Schnettler et al. 2010). Our previous study showed that the NSs gene can complement mutated HC-Pro to restore the potyviral pathogenicity in squash plants (Huang et al. 2015), implying functional similarity of NSs protein to HC-Pro. Moreover, specific motifs of NSs protein affecting viral symptoms and RSS function have been documented (de Ronde et al. 2014; Huang et al. 2015; Zhai et al. 2014). Although, the threedimensional structure of NSs protein is still unknown, previous studies showed that NSs protein may form oligomers (Huang et al. 2015; Schnettler et al. 2010). The self-interaction of the capsicum chlorosis virus NSs protein has been demonstrated by bimolecular fluorescence complementation (BiFC) (Widana Gamage and Dietzgen 2017). However, a comprehensive knowledge of self-interaction of NSs protein is still lacking and the essential aas and motifs involved in NSs self-interaction have not been identified.

RSSs of many plant viruses determine their pathogenicity and symptom development, as shown for p19 protein of tombusvirus (Qiu et al. 2002), P25 protein of potato virus X (Aguilar et al. 2015), potyviral HC-Pro protein (Shiboleth et al. 2007; Wu et al. 2010), and tospoviral NSs protein (Huang et al. 2015; Kormelink et al. 1991). We have previously developed attenuated vectors from several potyviruses, including zucchini yellow mosaic virus (Lin et al. 2007) and TuMV (Kung et al. 2014), that cause infection with inconspicuous symptoms and can effectively express foreign protein in planta. They are useful tools for the assay of pathogenicity functions of viral genes of interest. In this study, the TuMV mild vector TuKGFP, which has a R182K mutation in the FRNK motif of
HC-Pro and induces infection with inconspicuous symptoms in Nicotiana benthamiana plants (Kung et al. 2014), was used to analyze the pathogenicity of the WT and mutated NSs proteins in $N$. benthamiana plants.

In this study, using deletion and mutation analyses on WSMoV NSs protein, we examined self-interaction of WSMoV NSs protein and found that a putative $\alpha$-helix structure at the Cterminal region (aa 338 to 360 , denoted as the $\mathrm{H} 8$ helix) is involved in self-interaction and that the H8 helix affects RSS function. NSs protein with a mutation of three aas in H8, denoted as triple-point mutant (TPM) NSs lacks self-interaction ability, though its siRNA-binding ability is unaffected. Altogether, we conclude that the $\mathrm{H} 8$ helix in the C-terminal region of WSMoV NSs protein is crucial for self-interaction that stabilizes the protein to maintain RSS function and pathogenicity.

\section{RESULTS}

\section{Secondary structure prediction of WSMoV NSs protein} and generation of different deletion mutants.

The present investigation was to determine the sequence motifs involved in the self-interaction of WSMoV NSs protein and to assess the importance of self-interaction for the protein structural stability and functions. The secondary structural analysis by POLYVIEW 2D (two-dimensional) software (available online) predicted the presence of 10 putative $\alpha$-helices (H1 approximately 10) in WSMoV NSs protein (Fig. 1A). In order to determine the involvement of these putative $\alpha$-helices in the self-interaction of WSMoV NSs protein, different parts of the $\mathrm{N}$ - or C-terminal regions of the NSs protein were deleted to generate eight different deletion mutants, $\Delta \mathrm{N}, \Delta \mathrm{C}, \Delta \mathrm{N} 111$, $\Delta \mathrm{N} 158, \Delta \mathrm{N} 193, \Delta \mathrm{C} 331, \Delta \mathrm{C} 360$, and $\Delta \mathrm{C} 407$, as depicted in Figure 1B.

\section{The C-terminal half of WSMoV NSs protein is more important than the $\mathrm{N}$-terminal half for self-interaction.}

The self-interaction ability of NSs protein deletion mutants were analyzed by co-immunoprecipitation (co-IP). Individual NSs deletion mutants were Myc-tagged and expressed by bacteria. After purification through an amylose-resin column, each protein was mixed with bacteria-expressed hemagglutinin (HA)-tagged WT NSs protein and was subjected to IP with antiHA antibody. The coimmunoprecipitated proteins were analyzed by Western blotting using anti-Myc antibody. The results revealed the strongest interaction of the $\mathrm{N}$-terminal deletion mutant $\Delta \mathrm{N}$ with WT NSs protein. However, the deletion mutants $\Delta \mathrm{C}, \Delta \mathrm{N} 111$, and $\Delta \mathrm{C} 407$ showed much weaker interaction with WT NSs protein, as compared with other mutants analyzed (Fig. 2A). These results implied the possibility that more than one motif from the $\mathrm{N}$ - or $\mathrm{C}$-terminal half of the protein might be involved in NSs protein self-interaction.

We further analyzed NSs protein self-interaction by yeast two-hybrid (YTH) assay. Our data showed that none of the NSs deletion mutants showed any sign of self-interaction (data not shown). Similarly, $\Delta \mathrm{C}$ deletion mutant protein also did not interact with the WT NSs protein. However, a weak interaction between $\Delta \mathrm{N}$ deletion mutant and WT NSs protein was observed (Fig. 2B, left panel). Hence, the interaction between each deletion mutant NSs protein and full-length WT NSs protein were further examined. Our results showed that $\Delta \mathrm{N} 158$ and $\Delta \mathrm{N} 193$ deletion mutants interacted with WT NSs protein, but $\Delta \mathrm{N} 111$, $\Delta \mathrm{C} 331, \Delta \mathrm{C} 360$, and $\Delta \mathrm{C} 407$ proteins did not (Fig. 2B, right panel).

Taken together, the results of co-IP and YTH assays suggested that the $\mathrm{C}$-terminal half of the NSs protein (aa residues 215 to 439) is more important for self-interaction. However, possible subordinate roles of the N-half of the protein (aa 
residues 1 to 111 ) in NSs protein self-interaction cannot be ruled out.

\section{A putative $\alpha$-helix 8 at the $\mathrm{C}$-terminal region} of the NSs protein is crucial for self-interaction.

In protein-protein interaction, protein domains containing $\alpha$-helices play critical roles. Induced changes in such $\alpha$-helices may alter or abolish protein-protein interaction (Azzarito et al. 2013). According to results illustrated in Figure 1A, there are five putative helices at the C-terminal half of NSs protein (aa 215 to 439). Among them, the confidence level of the prediction of aa 338 to 360 region (denoted as H8, the eighth putative helix at NSs protein) of the secondary structure is higher (Fig. 1A) than confidence levels of the other nine helices
(Fig. 1A). Therefore, the $\Delta \mathrm{H} 8$ (aa 338 to 359 deleted) mutant protein was constructed for further investigation. In addition, five charged or aromatic aa of Y338, K344, H350, F353, and E359 within the H8 helix were also alanine-mutated (Y338A, K344A, H350A, F353A, and E359A) for self-interaction analyses. The YTH assay showed that $\triangle \mathrm{H} 8, \mathrm{Y} 338 \mathrm{~A}, \mathrm{H} 350 \mathrm{~A}$, and F353A mutants lost their self-interaction abilities with WT NSs protein (Fig. 3A). Furthermore, the TPM protein (Y338A/H350A/F353A) did not self-interact (Fig. 3A), indicating that three individual single point-mutations at the three aromatic residues of $\mathrm{H} 8$ (Y338A, H350A, and F353A) affects self-interaction of NSs protein.

Because yeast vectors pGBT9 and pGAD424 are low protein-expression vectors. The proteins with all NSs mutated

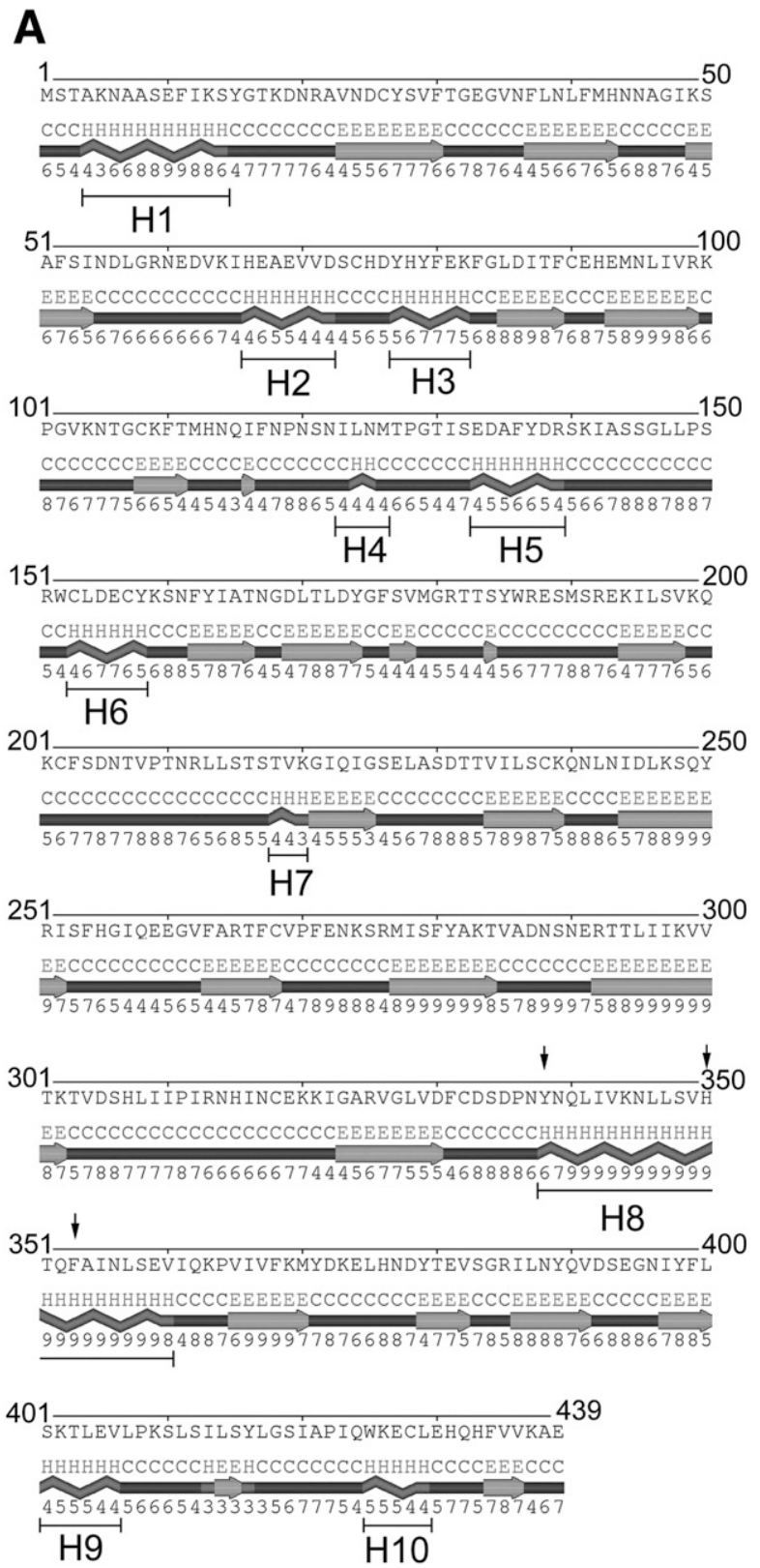

B

Full length
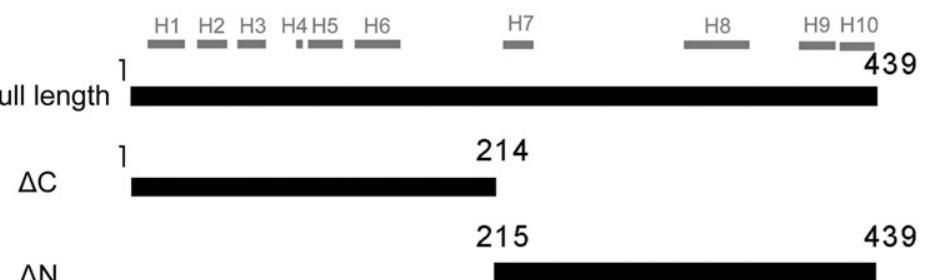

$\Delta \mathrm{N}$
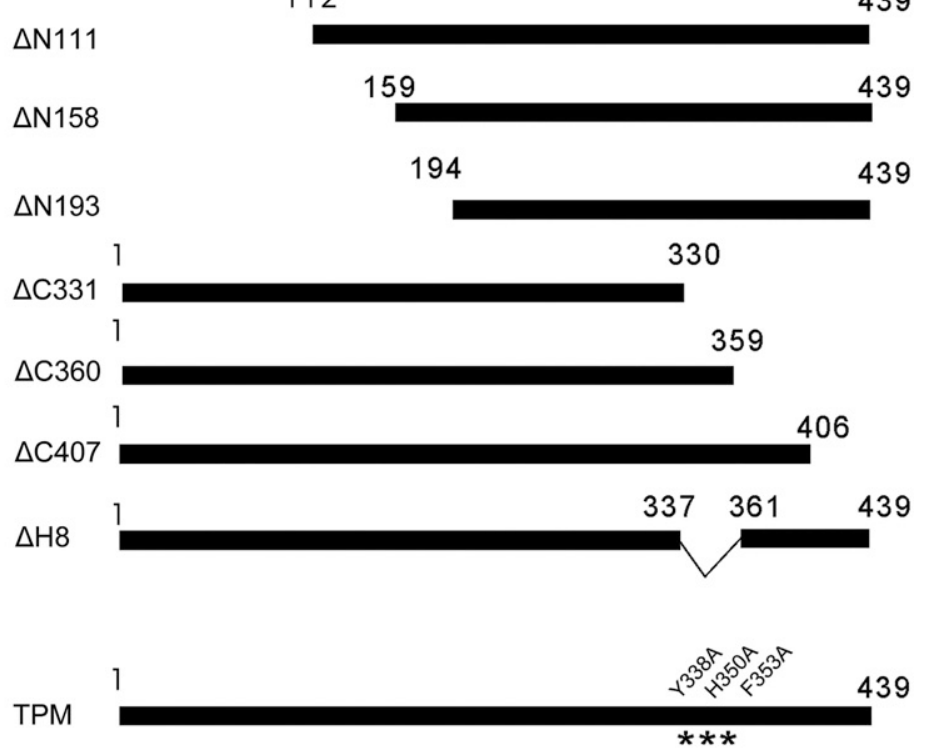

Fig. 1. Generation of deleted or mutated nonstructural protein S (NSs) of watermelon silver mottle virus (WSMoV) for analysis of self-interaction ability. A, Prediction of NSs secondary structure. NSs sequence was analyzed by POLYVIEW 2D software. Wave line (H): $\alpha$ and other helices; arrow: $\beta$-strand or bridge; straight line: coil. Numbers below the diagram of the secondary structure indicate confidence level of prediction. The amino acid (aa) positions indicated by small arrows, above the $\mathrm{H} 8$ region, were chosen for alanine-mutagenesis. B, Schematic representation of deleted or mutated NSs constructs in this study. The aa positions of the individual fragments corresponding to the NSs reading frame of WSMoV are indicated. The aa residues indicated by stars (*), located in $\mathrm{H} 8$ region, were chosen for alanine mutagenesis in this study. TPM = triple point mutation. 
are undetectable. Hence, in order to further confirm the selfinteraction ability of the $\Delta \mathrm{H} 8$ mutant, single-point mutants, and the TPM mutant, a BiFC assay was conducted. The open reading frame (ORF) of NSs protein and its mutants was fused with the $\mathrm{N}$ - or the $\mathrm{C}$-terminal half of enhanced yellow fluorescent protein (NEYFP or CEYFP, respectively) at either the $\mathrm{N}$ terminus or the $\mathrm{C}$ terminus. The constructs were coagroinfiltrated into $N$. benthamiana leaves and their EYFP signals were observed by confocal microscopy at 2 days postagroinfiltration (dpa). The results of $\mathrm{BiFC}$ revealed that the self-interactions of WT-NSs, tagged with NEYFP or CEYFP at either N-terminal or C-terminal end, displayed strong distribution of EYFP signals in the periphery membrane of cells and also appeared as dot aggregates in cytoplasm (Fig. 3B). Our results indicated that NEYFP or CEYFP fused at either the $\mathrm{N}$ - or C-terminal end of NSs protein does not affect NSs

A Input

IP: anti-HA

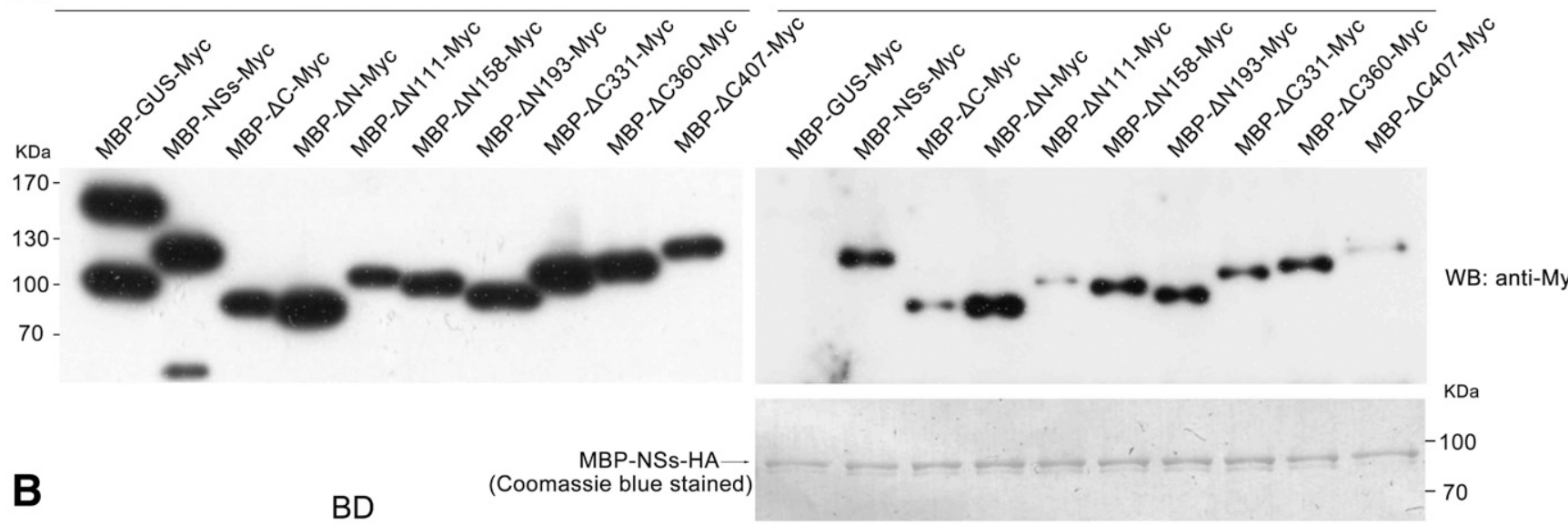

$\mathrm{AD}$

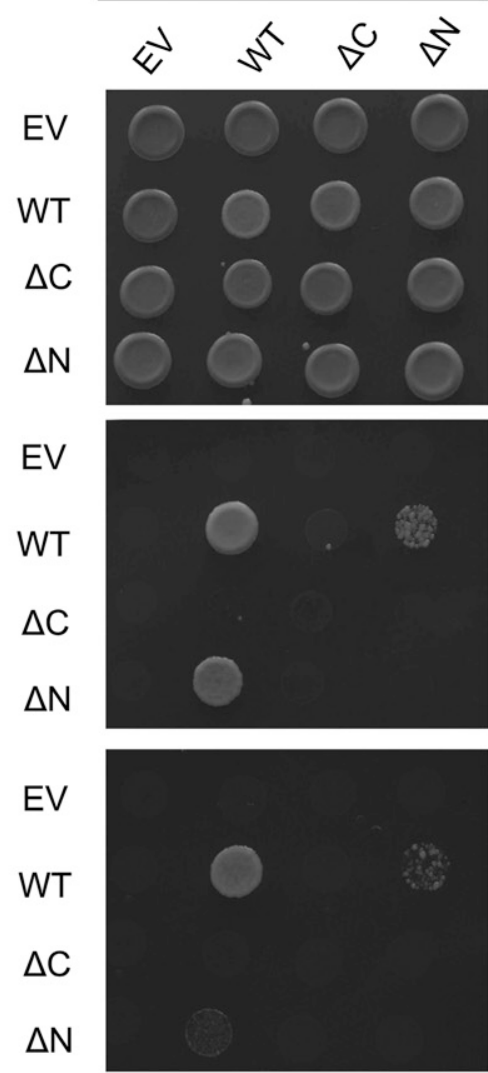

章

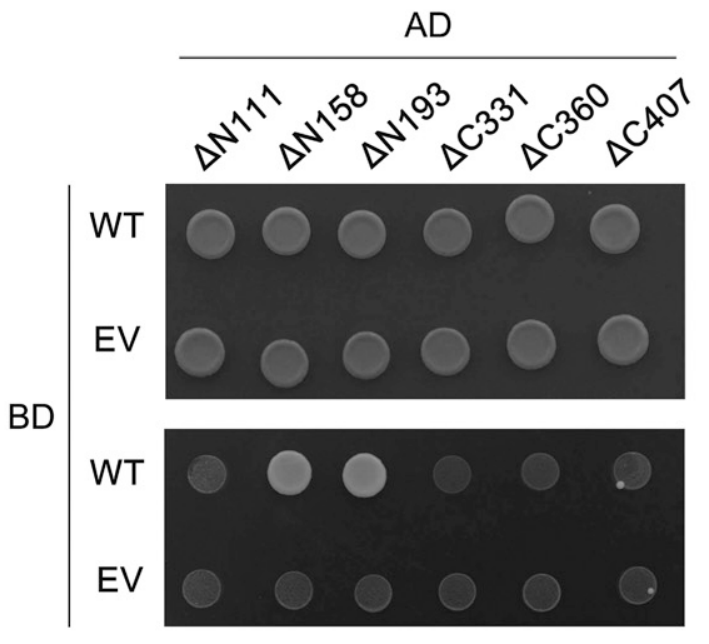

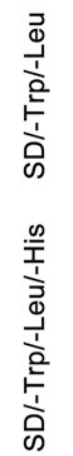

Fig. 2. Analyses of the role of the N-terminal and C-terminal halves of nonstructural protein S (NSs) of watermelon silver mottle virus for self-interaction. A, Analysis of individual deletion NSs proteins for self-interaction by coimmunoprecipitation. Each amylose-resin purified bacteria-expressed deletion mutant NSs protein tagged with Myc was mixed with hemagglutinin (HA)-tagged wild-type (WT) NSs and was subjected to immunoprecipitation (IP) with anti-HA antibody followed by Western blotting, using anti-Myc antibody. Left panel: detection of total mixed proteins using anti-Myc antibody (input); right panel: detection of immunoprecipitated proteins using anti-Myc antibody. Coomassie blue-stained HA-tagged NSs proteins were used as loading controls. B, Analysis of individual deletion NSs proteins for self-interaction by yeast two-hybrid analysis. Left panel: Plasmids with DNA-binding domain (BD) carrying the empty vector (EV), wild type (WT), $\Delta \mathrm{C}$ or $\Delta \mathrm{N}$ NSs constructs were cotransformed with plasmids with activation domain (AD) carrying each of the subsets shown above, respectively, into Saccharomyces cerevisiae cells and the transformed cells were then grown on synthetic define (SD) medium lacking leucine (Leu) and tryptophan (Trp) or histidine, Leu, and Trp with or without $20 \mathrm{mM} 3$-amino-1,2,4-triazole (3-AT). Right panel: interactions between individual deletion NSs proteins $(\Delta \mathrm{N} 111, \Delta \mathrm{N} 158, \Delta \mathrm{N} 193, \Delta \mathrm{C} 331, \Delta \mathrm{C} 360$, or $\Delta \mathrm{C} 407)$ and WT NSs protein. 
self-interaction in plant cells. Taken together, we demonstrate that tospoviral NSs protein has the ability to self-interact in vitro and in vivo, i.e., in yeast and in plant cells.

In a self-interaction assay, all C- or N-terminal half EYFPtagged single point-mutated NSs proteins showed selfinteraction YFP signals, similar to that of WT NSs protein. However, no self-interaction signal was observed for $\Delta \mathrm{H} 8$ and TPM proteins (Fig. 3B). The protein expression levels of $\Delta H 8$ CEYFP, TPM-NEYFP, and TPM-CEYFP were comparable to that of WT NSs (Fig. 3C). Furthermore, the interactions between WT and individual mutants were also analyzed. The results of the BiFC assay indicated that all the mutants except TPM interacted with WT (Supplementary Fig. S1). Thus, our BiFC assay results indicate that single mutations of three aa residues, Y338, H350, and $\mathrm{F} 353$, does not interfere significantly with NSs protein self-interaction, but the deletion of $\mathrm{H} 8$ or mutations of all three residues abolish the self-interaction ability.

Moreover, the in-vitro pull-down assay results also showed much weaker interaction, at a hardly detectable level, between TPM and WT proteins, as compared with the self-interaction of WT protein (Fig. 3D). The in-vitro interaction of TPM protein was not analyzed due to instability of other tag-fused TPM recombinant protein. Overall, our results demonstrated that the putative helix $\mathrm{H} 8$ at the C-terminal region (aa 338 to 360) of the NSs protein, especially its aa residues Y338, H350, and F353, is crucial for self-interaction.

\section{$\triangle H 8$ and TPM mutants affect protein stability and RSS function of NSs protein.}

To address the importance of self-interaction of NSs protein for the RSS function, individual mutated proteins were coexpressed with a green fluorescent protein (GFP) expresser and a hairpin GFP-silencing inducer into leaf tissues of a $N$. benthamiana plant through agroinfiltration. No GFP fluorescence was observed in leaf tissues agroinfiltrated with the empty vector (EV). On the contrary, strong GFP fluorescence was observed in the leaf tissues agroinfiltrated with constructs expressing WT NSs protein or each single point mutated Y338A, K344A, H350A, F353A, or E359A protein (Fig. 4A). However, GFP fluorescence was hardly observed in leaf tissues agroinfiltrated with vectors expressing $\triangle \mathrm{H} 8$ or TPM protein (Fig. 4A), indicating that these mutants lost their RSS function.

In Western blotting, $\triangle \mathrm{H} 8$ and TPM proteins were detectable at $1 \mathrm{dpa}$ but not at $4 \mathrm{dpa}$, suggesting that the translation of them was not blocked and that the loss of suppression ability at 4 dpa is probably due to instability of the mutated proteins in the host (Fig. 4C). On the other hand, when the leaves were agroinfiltrated with a higher concentration of Agrobacterium tumefaciens cultures, protein expression levels of $\Delta \mathrm{H} 8$ and TPM were also detectable at $4 \mathrm{dpa}$ (Fig. 4D), reflecting a dosedependent effect. Moreover, in order to rule out the possibility of the degradation of mutated NSs mRNA by the host, $\Delta \mathrm{H} 8$ or the TPM mutant was co-agroinfiltrated with potyviral suppressor HC-Pro. Even in the presence of HC-Pro, the accumulation levels of $\triangle \mathrm{H} 8$ and TPM mutant proteins did not increase, although relatively higher levels of accumulation of their mRNA were noticed (Fig. 4E; Supplementary Fig. S2).

\section{Weaker RSS ability of $\triangle \mathrm{H8}$ and TPM mutant is not due to compromised RSS but to protein instability; mutant monomers retain RSS ability.}

In addition, we compared $\triangle \mathrm{H} 8$ and TPM mutants with the point mutants R181A and Y398A, which we previously constructed and analyzed (Huang et al. 2015). R181A mutant expresses to the WT level but is RSS-defective due to impairment of the RSS functional motif, while Y398A mutant is RSS nonfunctional due to protein instability (Huang et al. 2015). In order to analyze the influence of protein instability on RSS function, the concentrations of A. tumefaciens carrying $\mathrm{pBCo}-\mathrm{NSs}, \mathrm{pBCo}-\Delta \mathrm{H} 8, \mathrm{pBCo}-\mathrm{TPM}, \mathrm{pBCo}-\mathrm{R} 181 \mathrm{~A}$, or pBCo-Y398A were increased to see the effect on RNAsilencing activity. The RSS function and protein expression levels of individual mutants with a higher concentration (optical density at $600 \mathrm{~nm}\left[\mathrm{OD}_{600}\right]=2.0$ ) of A. tumefaciens were analyzed at $4 \mathrm{dpa}$. The intensity of GFP fluorescence of WT-, $\Delta$ H8-, TPM-, R181A-, or Y398A-infiltrated leaf tissue was relatively greater than that of EV-infiltrated leaf tissue, with $100,5,27,11$, or $45 \%$ increase, respectively (Fig. 5A). However, the R181A mutant protein amount was much higher than that of $\triangle \mathrm{H} 8$ and TPM (Fig. 5B), indicating $\triangle \mathrm{H} 8$ and TPM proteins have stronger RSS activity than R181A. To estimate the relative RSS capacity of individual NSs proteins, GFP fluorescence intensity/NSs protein ratios were analyzed, revealing the ratios of TPM and Y398A proteins were higher than those of WT and R181A proteins (Fig. 5C), suggesting the RSS capability of TPM protein is strong, but protein instability affects its final RSS outcome. These results indicated that host RNA-silencing activity was blocked by $\Delta \mathrm{H} 8$ and TPM mutants in a dose-dependent manner, similar to the previously described mutant Y398A (Huang et al. 2015). Hence, our data suggested that monomeric (non-selfinteracting) NSs mutant protein has RSS function and its protein stability affects RSS function. However, TPM mutant instability decreases its protein level and, consequently, decreases RSS activity level in the TPM agroinfiltrated area.

Taken together, the weaker RSS function of the $\Delta \mathrm{H} 8$ and TPM mutants, which lack self-interaction ability, is positively correlated to their protein amount. Hence, our data suggested that monomeric (non-self-interacting) NSs mutant protein has the RSS function, but its protein stability affects RSS function.

\section{TPM protein binds to the siRNA duplex in vitro.}

The ability to bind siRNA is crucial for a plant virussilencing suppressor to effectively overcome a defense process initiated by the plant (Lakatos et al. 2006; Vargason et al. 2003). To dissect whether self-interaction of WSMoV NSs protein is important for its siRNA binding ability and the relationship with RSS function, an electrophoretic mobility shift assay (EMSA) was performed. In EMSA, maltose binding protein (MBP)-fused recombinant proteins tagged with $\mathrm{HA}$ and expressed by Escherichia coli were used for binding a ${ }^{32} \mathrm{P}$-labeled siRNA duplex. The expression of each recombinant protein was assessed by Western blot using anti-HA antibody (Fig. 6A). In EMSA, no shifted band was observed for the negative control, i.e., MBP-fused $\beta$-glucuronidase protein with the siRNA duplex (Fig. 6B). On the contrary, a shifted band was observed from WT NSs protein, indicating its ability to bind siRNA. Our results corroborated an earlier finding that various species of orthotospoviral NSs proteins bind to RNA duplexes (Schnettler et al. 2010). Intriguingly, the TPM protein showed unaffected siRNA binding ability, as evidenced by the retarded band representing the TPM protein-siRNA complex in EMSA (Fig. 6B). We also tested the siRNA affinity of mutants H113A and Y398A, in which RSS function was hampered due to the instability of mRNA and protein instability, respectively (Huang et al. 2015). For H113A, the siRNA binding ability was abolished, as no shifted band was detected in EMSA. However, for the mutation that affects protein stability, Y398A protein, the EMSA result indicated 
A

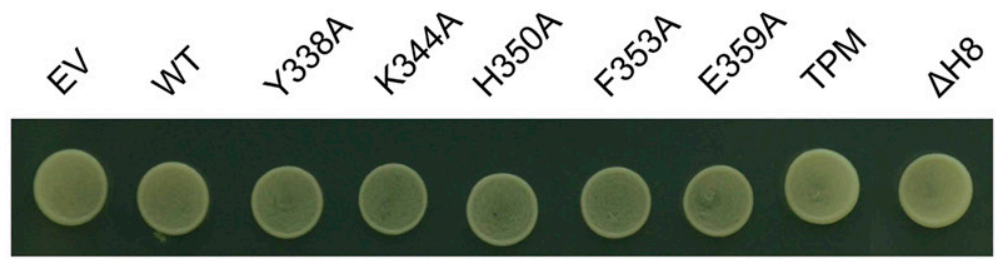

$\mathrm{SD} /$-Trp/-Leu

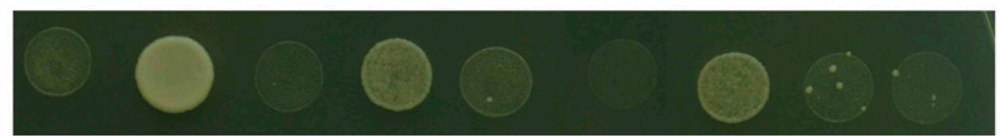

SD/-Trp/-Leu/-His

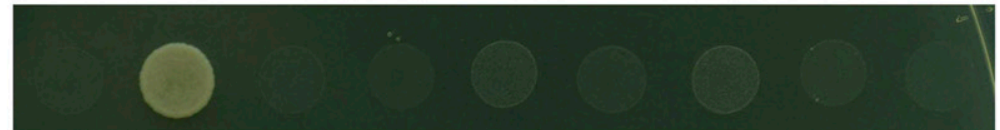

$\mathrm{SD} /$-Trp/-Leu/-His with $20 \mathrm{mM}$ 3-AT

B

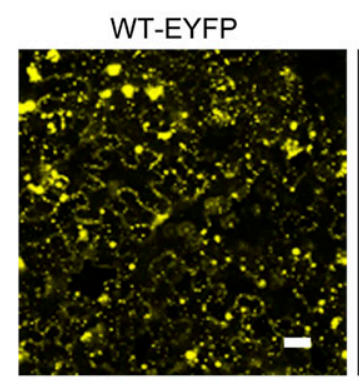

WT-N/WT-C

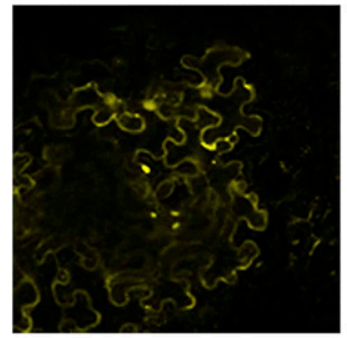

H350A-N/H350A-C

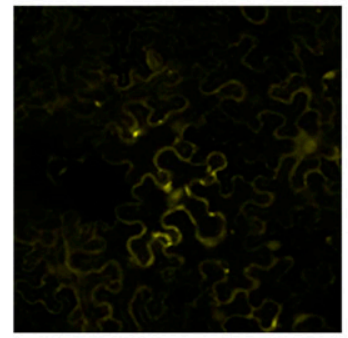

F353A-N/F353A-C

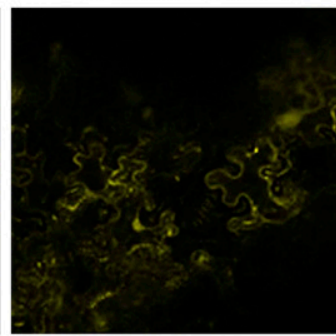

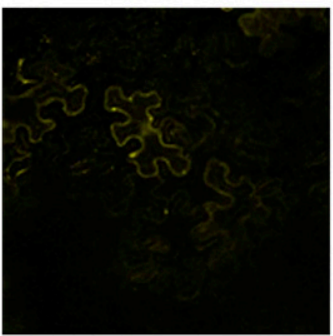

N-WT/C-WT

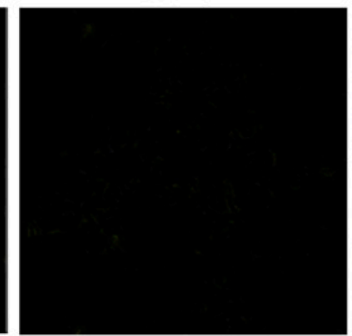

Y338A-N/Y338A-C

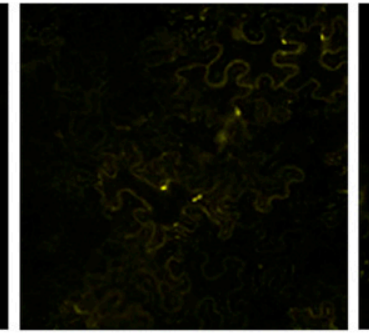

K344A-N/K344A-C

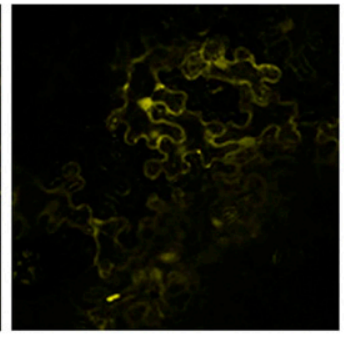

TPM-N/TPM-C

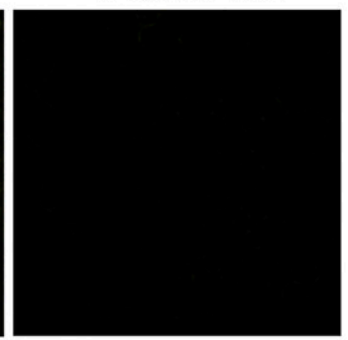

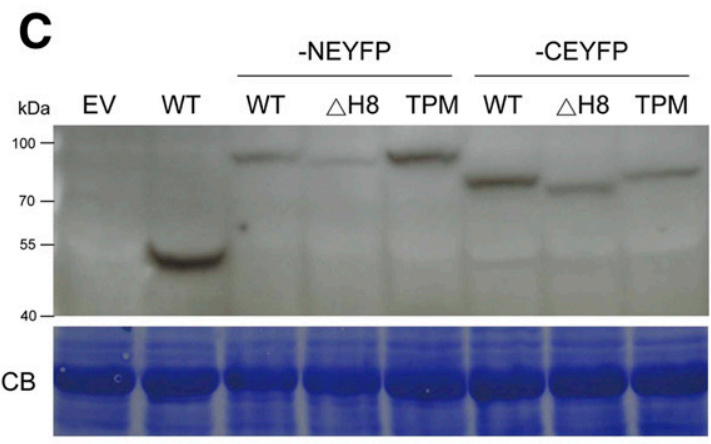

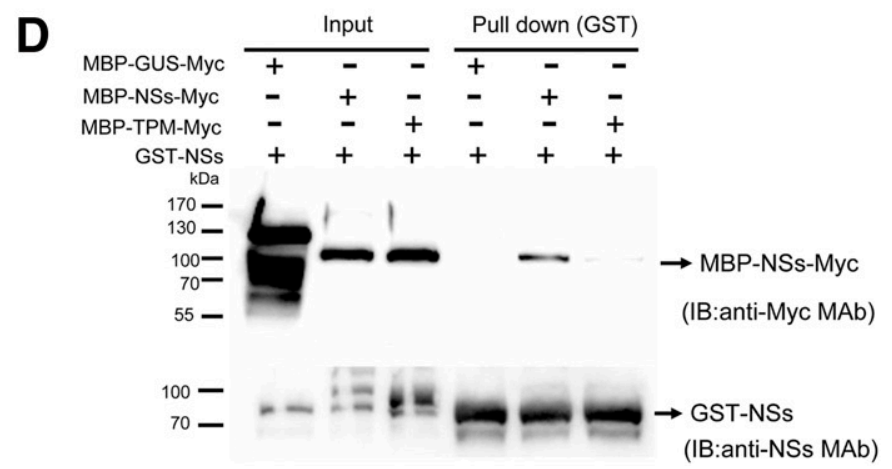


that complexes were formed between protein and the siRNA duplex, implying that the Y398A protein is functional in siRNA binding.

Taken together, our results indicated that self-interaction of NSs protein is important for protein stability and consequent function as an effective RSS. However, self-interaction of NSs protein is not essential for siRNA binding ability.

\section{WT NSs but not TPM protein complements} the pathogenicity function of TuMV HC-Pro.

In this investigation, we analyzed the pathogenicity of the WT NSs protein and mutated NSs proteins, using the attenuated potyviral vector TuK-GFP infecting $N$. benthamiana without conspicuous symptoms due to $\mathrm{R}^{182} \mathrm{~K}$ mutation in the FRNK motif of HC-Pro (Kung et al. 2014). The GFP ORF between the NIb gene and the coat protein $(\mathrm{CP})$ gene of TuK-GFP was replaced with WT NSs or individual mutated NSs proteins. The $N$. benthamiana plants inoculated with TuK-WT NSs showed symptoms of severe mosaic and distortion in shrunken systemic leaves, similar to those induced by the severe parental TuMV strain (Fig. 7A) but without wilting, at 10 days postinoculation (Fig. 7B); however, the development of severe symptoms was delayed by 2 to 3 days. These results indicated that the WT NSs can restore the pathogenicity of the attenuated $\mathrm{TuK}$ in N. benthamiana plants (Fig. 7).

On the contrary, when the TuK recombinant viruses carrying individual NSs mutants, TuK-Y398A, TuK-TPM, and TuK- $\Delta \mathrm{H} 8$ were used for assay, the inoculated $N$. benthamiana plants displayed inconspicuous symptoms (Fig. 7A and B) similar to those induced by TuK-GFP, i.e., transient mildmottling in inoculated leaves followed by recovery in systemic leaves (Fig. 7A and B). In Western blotting using NSs monoclonal antibody (Chen et al. 2006), the expression of all mutant proteins was detectable (Fig. 7C) at 10 days postinoculation, however, at lower levels than that of WT NSs protein.

\section{DISCUSSION}

Investigations that provided evidence for self-interaction of orthotospovirus NSs proteins (Huang et al. 2015; Schnettler et al. 2010) have not described the identity and nature of the NSs self-interaction domain. However, earlier, we found that the $\mathrm{Y}^{398} \mathrm{~A}$ mutant of WSMoV NSs protein was relatively unstable and weaker in self-interaction (Huang et al. 2015). In this study, using different point mutants and deletion mutants of WSMoV NSs protein, we determined the sequence elements and individual aa sites involved in WSMoV NSs protein self-interaction and the importance of self-interaction for the structural stability and functions of the protein.

\section{Protein structural element or elements involved in WSMoV NSs protein self-interaction.}

As indicated by our results, the C-terminal half of NSs protein is more important in WSMoV NSs protein self-interaction than the N-terminal half of the protein. In tomato spotted wilt virus (TSWV), the C-terminal motifs of NSs protein were suggested to play a structural role rather than a role in RSS and avirulence activities (de Ronde et al. 2014). A recent report pointed out that the NSs protein of capsicum chlorosis virus $(\mathrm{CaCV})$ can self-interact, as indicated by BiFC assay (Widana Gamage and Dietzgen 2017). However, the nature and identity of the interacting domain has not been described. In the present study, we found that the H8 helix is important for selfinteraction of NSs protein. However, $\Delta \mathrm{N} 111$ (aa 1 to $111 \mathrm{de}-$ leted) and $\Delta \mathrm{C} 407$ (aa 407 to 439 deleted), both containing an H8 helix, showed weaker binding activity to WT NSs in an invitro co-IP assay (Fig. 2A), implying that $\mathrm{H} 8$ might not be the only motif involved in self-interaction of NSs protein. In a YTH assay, we found that individual $\alpha$-helix deletion mutants did not self-interact; only $\Delta \mathrm{N}$ (aa 1 to 214 deleted), $\Delta \mathrm{N} 158$ (aa 1 to 158 deleted), and $\Delta \mathrm{N} 193$ (aa 1 to 193 deleted) proteins, which contain an $\mathrm{H} 8$ helix, interacted with the full-length NSs protein (Fig. 2B). Inability of $\Delta \mathrm{N} 111, \Delta \mathrm{C} 331, \Delta \mathrm{C} 360$, and $\Delta \mathrm{C} 407$ proteins to interact with full-length NSs protein (Fig. 2B) may be due to abnormal protein folding of the mutants or involvement of more than one domain in NSs self-interaction. Hence, we cannot exclude possible subordinate roles of a region upstream of aa 111, e.g., $\mathrm{H} 1$ to $\mathrm{H} 3$ and the $\alpha$-helices $\mathrm{H} 9$ and H10, in NSs self-interaction. Alternatively, these deletions may lead to changes in protein folding that do not support interaction of mutant proteins with WT NSs. In general, we conclude that the $\mathrm{H} 8$ helix in the $\mathrm{C}$-half of NSs protein plays an important role in self-interaction and protein stability. The possible involvement of other motifs will be investigated further in the future.

WSMoV NSs protein is expected to exist in its native structural state (with native folding and posttranslational modification) in its native host (plant) cells. But, in yeast cells, NSs protein may have differences in folding and posttranslational modifications and, hence, may show differences in its activities. Moreover, the yeast-expressed WT NSs and its mutants are difficult to detect because pGAD424 and pGBT9 are lower protein expression vectors for avoiding protein toxicity. Hence, the possibility of nonexpression or instability of these proteins in yeast cannot be ruled out. However, in order to obtain decisive data confirming the loss of self-interaction abilities of $\triangle \mathrm{H} 8$ and TPM proteins with WT NSs, we carried out BiFC (in planta) (Fig. 3B) and glutathione $S$-transferase (GST) pull-down (in vitro) (Fig. 3D) experiments. The in-planta expression of $\triangle \mathrm{H} 8$ and TPM proteins was confirmed by Western blotting analysis (Fig. 3C). Moreover, TPM protein expression

Fig. 3. Analyses of helix 8 (H8) at the C-terminal half of nonstructural protein S (NSs) of watermelon silver mottle virus for self-interaction by yeast twohybrid, bimolecular fluorescence complementation, and in-vitro pull-down assays. A, Self-interaction of individual mutated NSs proteins in yeast cells. Constructs carrying each of the empty vector (EV), wild type (WT), deletion mutant $\Delta$ H8 (amino acids 338 to 359 deleted), individual point-mutated NSs proteins within H8 (five alanine-mutated NSs proteins of Y338A, K344A, H350A, F353A, and E359A), or the triple-point mutated (TPM) protein (Y338A/H350A/F353A) fused with DNA-binding domain or activation domain constructs were cotransferred into Saccharomyces cerevisiae cells and were grown on synthetic defined (SD) medium lacking leucine (Leu) and tryptophan (Trp) or histidine, Leu, and Trp with or without 20 mM 3-amino-1,2,4-triazole (3-AT). B, The open reading frame (ORF) of wild type (WT) or each mutated NSs was fused upstream or downstream with either the N-terminal half (NEYFP, simplified as N) or C-terminal half (CEYFP, simplified as C) of enhanced yellow fluorescent protein (EYFP). The names of constructs above each photo indicate the order of NSs ORF and tagged N or C ORF from the $5^{\prime}$ to the $3^{\prime}$ terminus. Each NEYFP- or CEYFP-fused NSs mutant was expressed in Nicotiana benthamiana leaves by agroinfiltration, and EYFP signals were observed at 2 days post-agroinfiltration (dpa) by confocal laser scanning microscopy. Scale bar $=20 \mu \mathrm{m}$. C, Protein expression levels of the WT and mutated NSs proteins fused with NEYFP or CEYFP. Western blotting of total proteins extracted from agroinfiltrated $N$. benthamiana plants was conducted using NSs monoclonal antibody (MAb) (Chen et al. 2006) at 2 dpa. CB = Coomassie blue-stained total proteins used as loading controls. D, Analysis of interaction between WT NSs and TPM proteins by in-vitro pull-down assay. Each amylose resin-purified, bacteria-expressed WT NSs or TPM protein tagged with Myc was mixed with glutathione $S$-transferase (GST)-tagged WT NSs and was subjected to pull-down assay with GST resin, followed by Western blotting using anti-Myc MAb (upper panel) or anti-NSs MAb (lower panel). 
was confirmed also by the Western blotting (Fig. 3D) subsequent to the in-vitro pull-down assay for analyzing the interaction between WT NSs and TPM proteins. We consider the results from BiFC (Fig. 3B) more authentic than those from YTH (Fig. 3A).

\section{NSs self-interaction, stability, and functions.}

The other viral suppressors of p19 (Danielson and Pezacki 2013; Ye et al. 2003), cysteine-rich protein (Sun et al. 2013), p21 (Ye and Patel 2005), and B2 (Chao et al. 2005; Seo et al. 2012) must form a dimeric or oligomeric structure for binding siRNA duplex. However, both monomeric and oligomeric B2 have RSS function (Chao et al. 2005; Seo et al. 2012).
Interestingly, monomeric B2 has a stronger RSS activity and enhances the virus titer. The monomeric B2 interacts with the PAZ domain of DCL protein to suppress RNA-silencing activity. The monomers of begomovirus, AL2 protein, and curtovirus L2 protein suppress local silencing by interacting with adenosine kinase (Yang et al. 2007). Based on our results, the monomer of WSMoV NSs mutant protein has an siRNA binding ability (Fig. 6B) that is positively correlated to the function of RSS assay (Fig. 5A) and behaves in a dosagedependent manner (Fig. 4A and 5B). Also, as indicated in Figure 5C, the TPM monomer has RSS function similar to that of WT NSs protein, possibly in association with one or more host factors, to retain its RSS ability. However, the weaker RSS

\section{A}
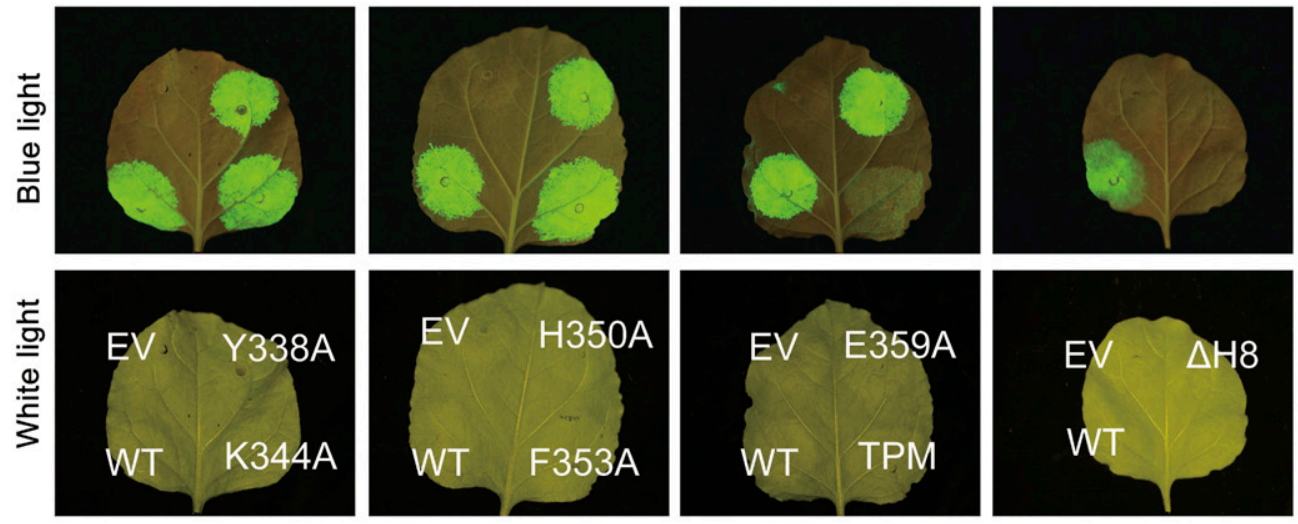

B
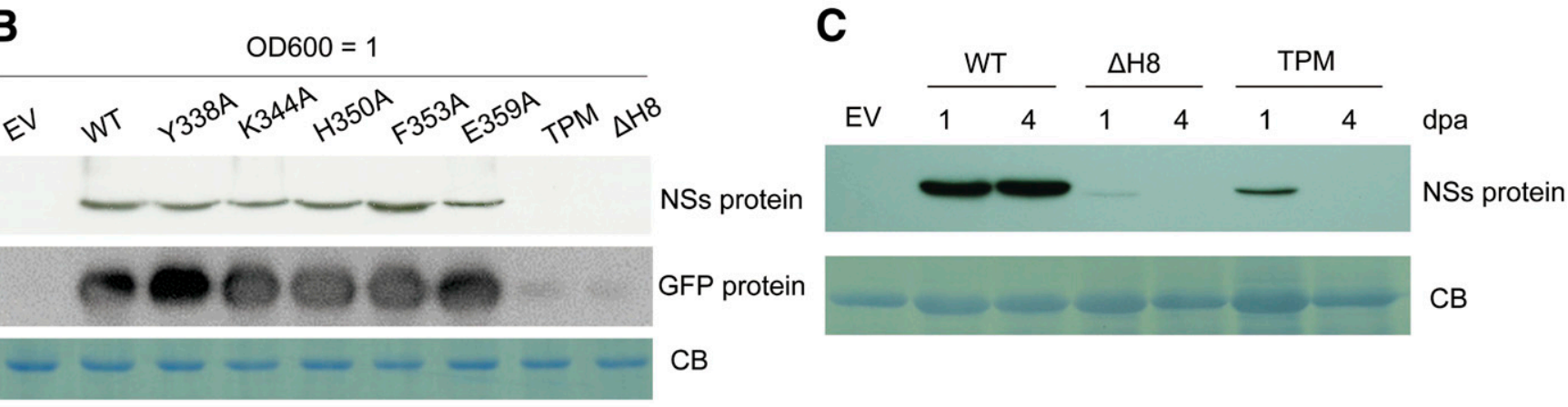

D
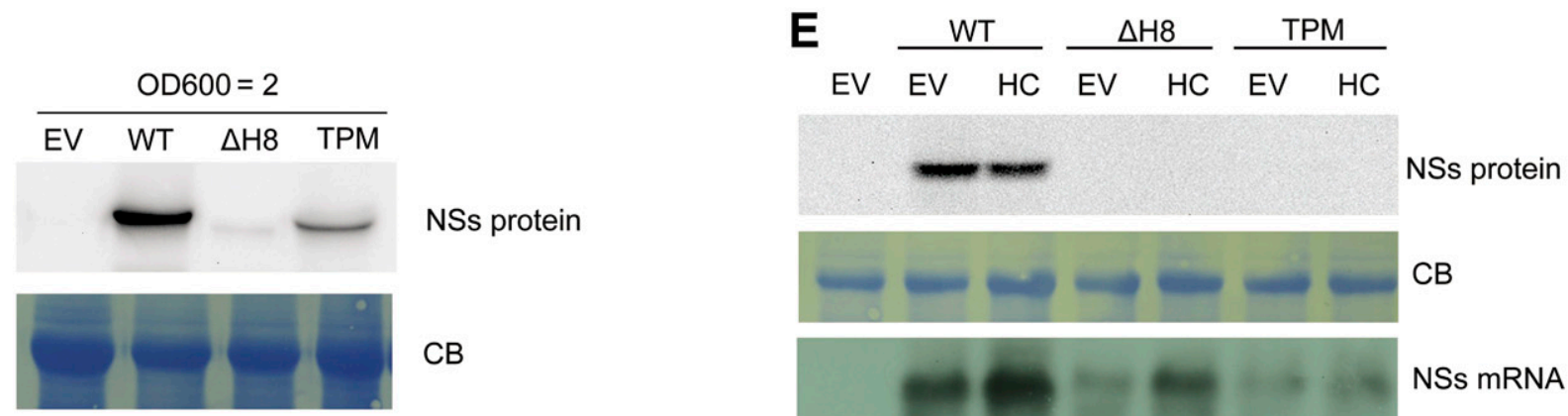

NSs protein

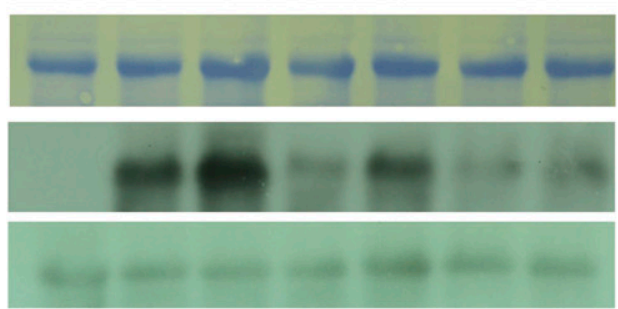

$\mathrm{CB}$

$\mathrm{CB}$

Fig. 4. Analysis of nonstructural protein S (NSs) proteins with the deletion of the C-terminal H8 helix ( $\Delta \mathrm{H} 8$, amino acids 338 to 359 deleted) or mutations within the H8 helix for RNA-silencing suppression. A, The leaf areas agroinfiltrated with individual mutated NSs constructs were examined under blue light. The green fluorescent protein (GFP) fluorescence was recorded at 4 days post-agroinfiltration (dpa), after coinfiltration of Agrobacterium carrying pBA-GFP (expresser), pBA-GFi (RNA-silencing inducer), and individual mutated NSs open reading frames. Empty vector (EV) represents negative control. The green fluorescence signals indicate the suppression function of the assayed protein. B, Expression levels of mutated NSs proteins and GFP were detected at 4 dpa by anti-NSs antibody or anti-GFP antibody, respectively. C, Protein expression levels of individual mutated NSs proteins at 1 or 4 dpa. D, Protein expression levels of individual mutated NSs proteins with a higher concentration of Agrobacterium cultures (optical density at $600 \mathrm{~nm}=2.0$ ) detected at $4 \mathrm{dpa}$. E, Expression levels of protein and mRNA of NSs mutants, following coinfiltration of the EV or potyviral silencing suppressor HC-Pro (HC), as detected at 4 dpa by anti-NSs monoclonal antibody and $\alpha-{ }^{32} \mathrm{P}$-labeled NSs probe, respectively. $\mathrm{CB}=$ Coomassie blue-stained total proteins were used as loading controls for proteins. $18 \mathrm{~S}$ ribosomal RNA was used as a loading control for RNAs. 
function of $\Delta \mathrm{H} 8$ and TPM proteins shown in Figure 4 is due to their protein instability. Moreover, we also examined whether degradation of $\triangle \mathrm{H} 8$ and TPM NSs mutants are via proteasomemediated degradation in the $N$. benthamiana plant. But our preliminary data indicated that $\triangle \mathrm{H} 8$ and TPM NSs mutant proteins still cannot be detected, when coinfiltrated with proteasome inhibitor (MG13-2) in the $N$. benthamiana plant by agroinfiltration. Thus, the detailed mechanism for the

A

NSs $\mathrm{OD}_{600}$
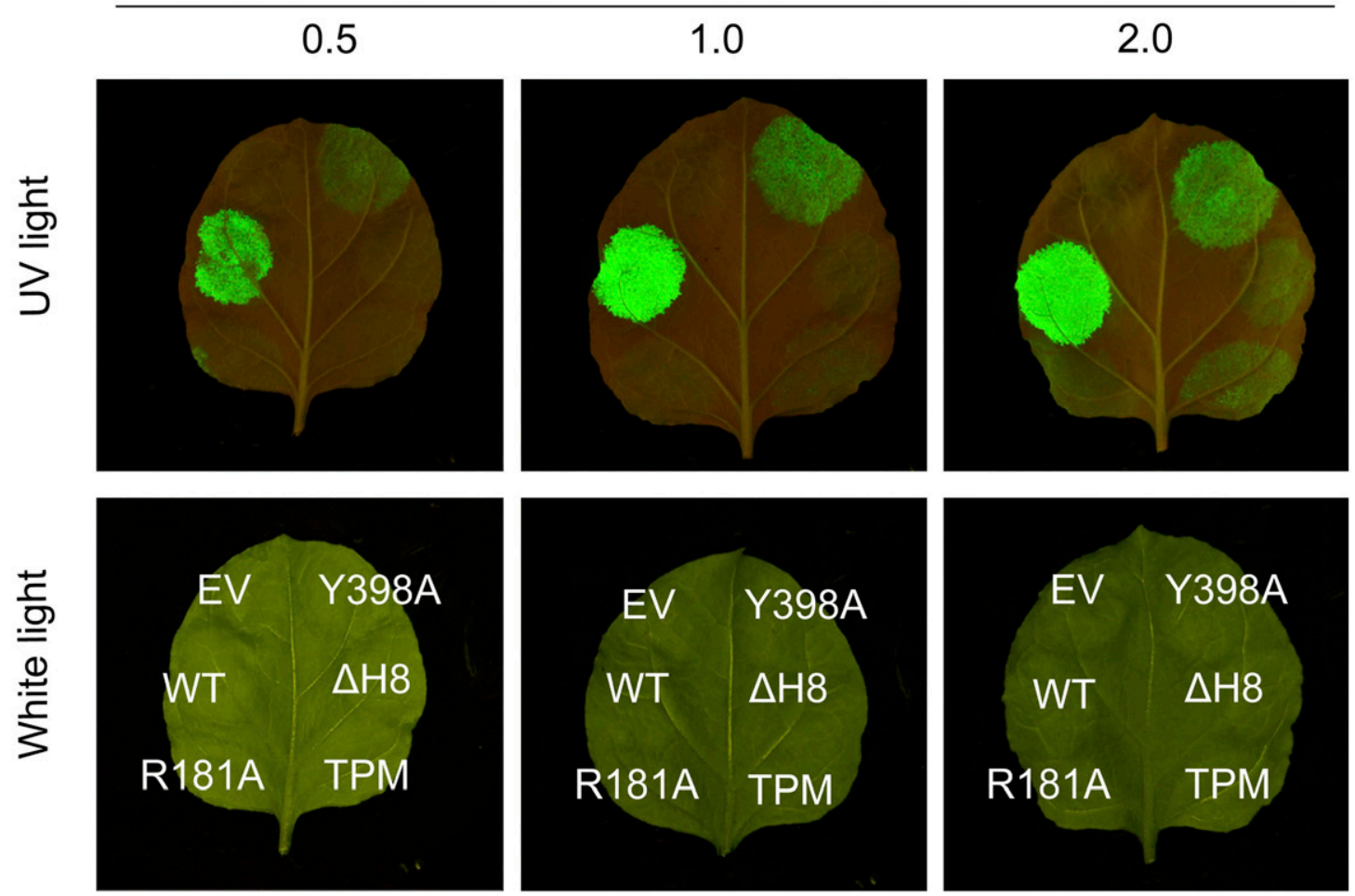

B

NSs $\mathrm{OD}_{600} 2.0$

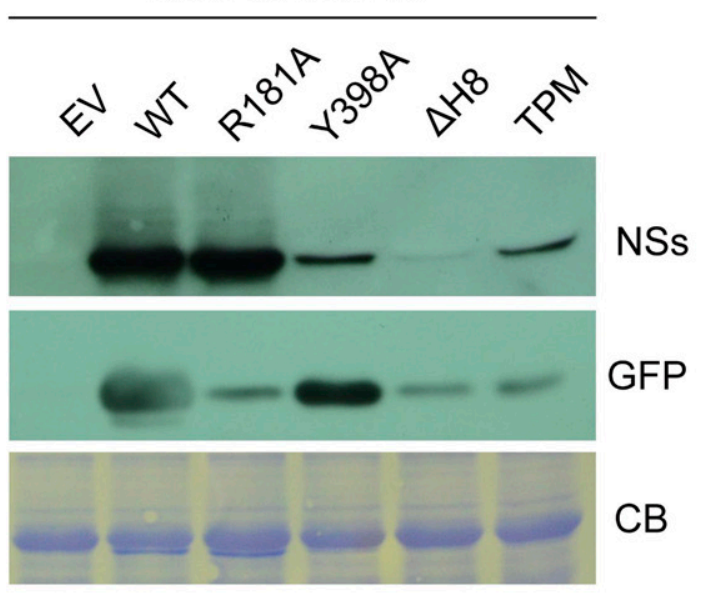

C

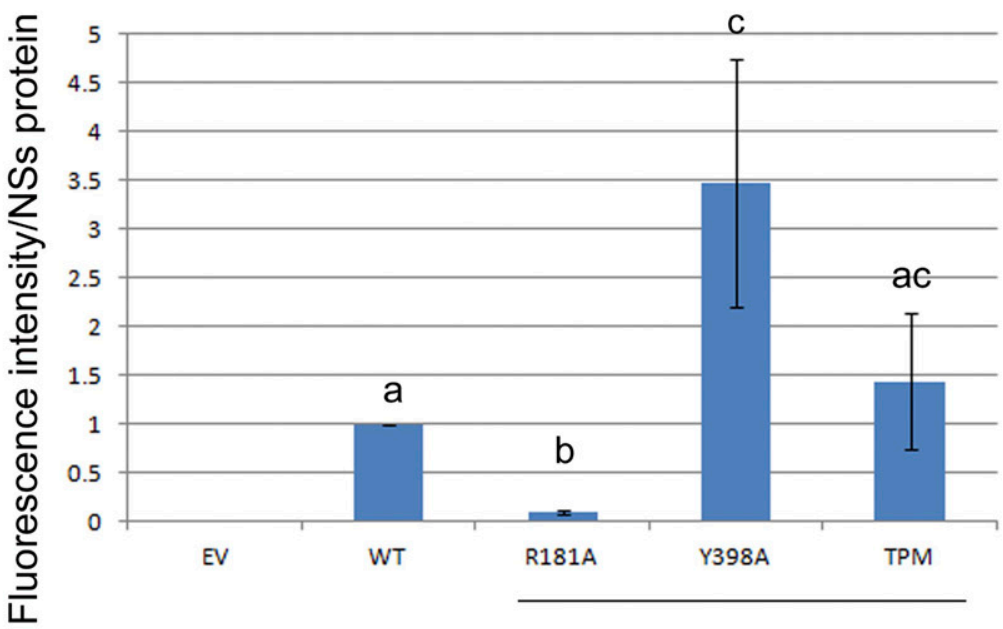

NSs mutants

Fig. 5. Analysis of RNA-silencing suppression capability of nonstructural protein $\mathrm{S}(\mathrm{NSs})$ proteins with a deletion of C-terminal $\mathrm{H} 8$ helix $(\Delta \mathrm{H} 8$, amino acids 338 to 359 deleted) or a triple point mutation (TPM, Y338A/H350A/F353A within H8 helix). A, Green fluorescent protein (GFP) intensity at leaf areas coinfiltrated with Agrobacterium cells carrying individual mutated NSs proteins, pBA-GFP (an expresser) and pBA-GFi (a silencing inducer) constructs, portrayed under white or blue light at 4 days post-agroinfiltration (dpa). Empty vector (EV) without NSs construct was used as the negative control. The R181A mutant defective in RNA-silencing suppressor function (Huang et al. 2015) and the Y398A mutant defective in protein stability (Huang et al. 2015) were used for comparison. The concentrations (optical density at $600 \mathrm{~nm}$ ) of Agrobacterium culture carrying individual NSs constructs are shown on the top of each panel. B, Western blotting was conducted for detection of wild type (WT) NSs and individual mutated proteins and GFP protein from the leaf areas coinfiltrated with Agrobacterium cultures carrying GFP, hairpin GFP, and individual NSs constructs. C, The number indicates the ratio of relative accumulation of GFP fluorescence relative to NSs protein coinfiltrated with GFP, GFi (a silencing inducer), and individual NSs constructs, as quantified by the Bio-Rad ChemiDoc MP imaging system and the ratio of fluorescence signals to NSs proteins were normalized with WT. Mean \pm standard deviation were from three independent experiments. The same letters indicate no significant difference $(P<0.05$, one-way analysis of variance, Holm-Sidak test). Total protein was extracted at 4 dpa. $\mathrm{CB}=$ Coomassie blue-stained total proteins used as loading controls. 
degradation of $\triangle \mathrm{H} 8$ and TPM NSs mutated proteins remains to be further investigated.

According to our previous studies, the common epitope (WNScon) of WSMoV NSs mutated protein is essential for NSs monoclonal antibody (MAb) recognition and is highly conserved in Asia-type orthotospovirus (Chen et al. 2006). Here, we show the evidence that the siRNA binding ability of H113 mutated protein was abolished (Fig. 6B). Thus, our results suggest that the loss of RSS ability of H113A protein is due to lack of siRNA binding ability.

Viral infection frequently induces the formation of proteinaceous inclusion bodies in host cells, such as potyviral HCPro (Riedel et al. 1998; Sahana et al. 2014) and caulimoviral p6 (Lutz et al. 2015; Shockey et al. 1980). The TSWV NSs protein can also form an inclusion body in infected host cells (Kormelink et al. 1991). The gene-silencing suppressor of tomato yellow leaf curl virus (TYLCV) V2 protein also forms aggregates and inclusion body and colocalizes with its $\mathrm{CP}$, which play an important role during TYLCV infection (Moshe et al. 2015). Recently, cauliflower mosaic virus gene-silencing suppressor P6 protein was shown to prevent its CP from autophagy-mediated degradation (Hafrén et al. 2017). The NSs protein of Asia-type orthotospovirus $\mathrm{CaCV}$ accumulates in both cell periphery membranea and the nucleus (Widana Gamage and Dietzgen 2017). We also found WSMoV NSs protein localization in the cell periphery and aggregation in cytoplasm, as reflected by EYFP signals (Fig. 3B). The aggregation of viral proteins in host cells are apparently formed through the selfinteraction of proteins that aggregate. Taken together, plant viral-silencing suppressors can form aggregates to protect themselves from host degradation mechanisms. In addition to the observation that NSs protein can self-interact in vitro and in vivo (Figs. 2, 3, and 4), we further showed that the monomeric form of NSs protein tends to be degraded in vivo (Fig. 4). Thus, we assume that NSs protein self-interaction and consequent dimerization/oligomerization and aggregation (as inclusion bodies) in the host cells prevent the degradation of NSs proteins and promote NSs protein functions.

Loss of the self-interaction ability of a viral RSS protein may affect accumulation and pathogenicity of the virus $(\mathrm{Xu}$ et al.

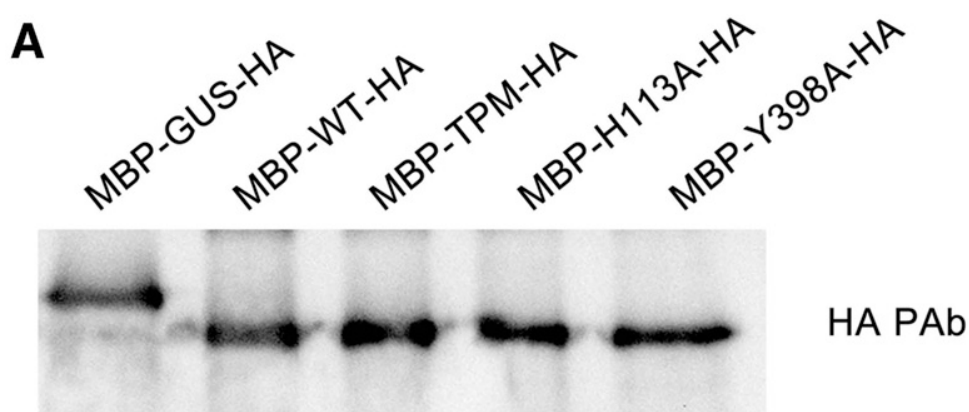

B

MBP- -HA
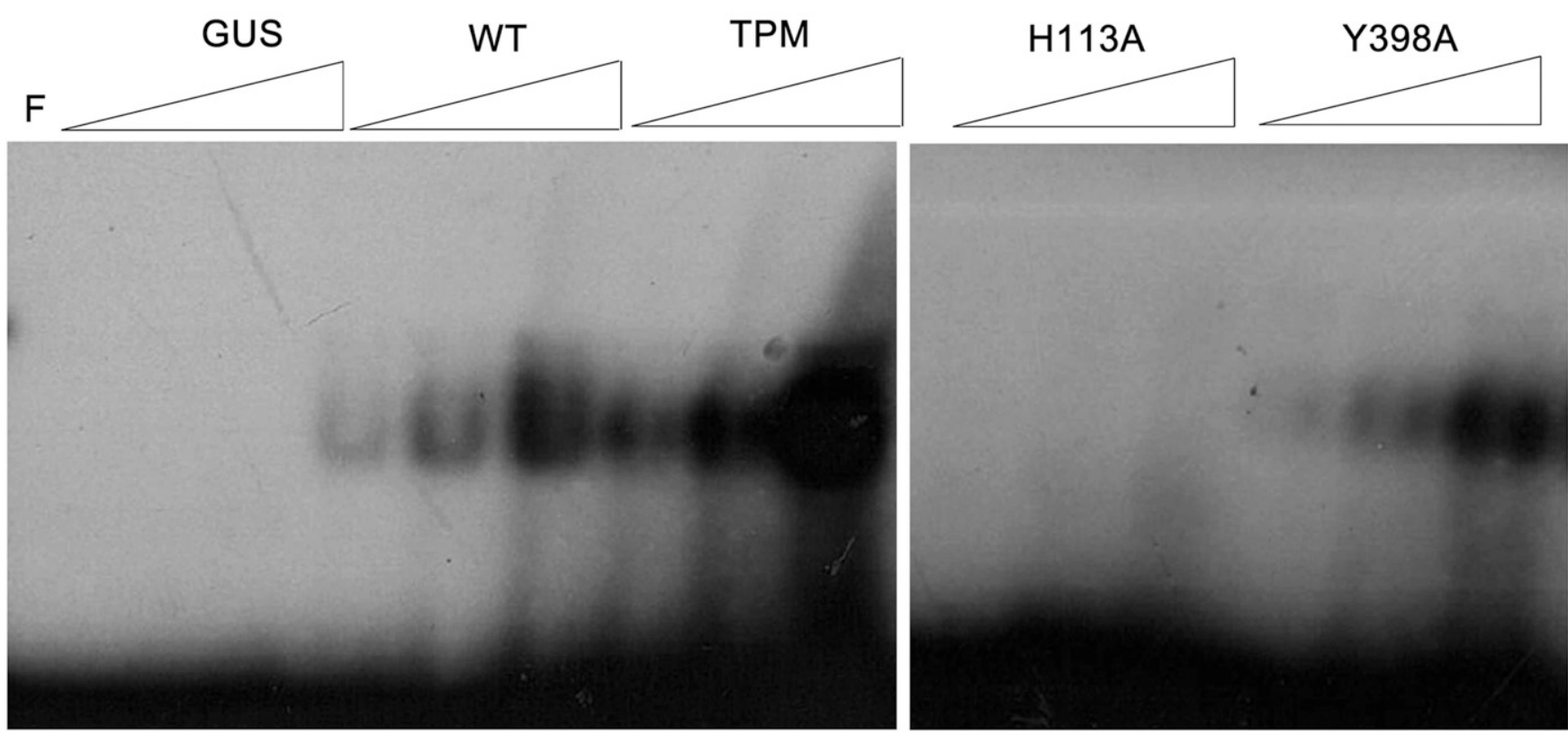

Fig. 6. Analysis of the small interfering RNA (siRNA) binding activity of nonstructural protein S or triple point mutation (TPM, Y338A/H350A/F353A within H8 helix) by electrophoretic mobility shift assay (EMSA). Escherichia coli-expressed maltose binding protein (MBP)-fused recombinant proteins MBP-GUSHA ( $\beta$-glucuronidase-hemagglutinin), MBP-WT-HA (wild type), and MBP-TPM-HA were used for a electrophoretic mobility shift assay (EMSA). The MBPH113A-HA mutant defective in mRNA stability and RNA-silencing suppressor function and the MBP-Y398A-HA mutant defective in protein stability (Huang et al. 2015) for comparison. A, Western blot analysis of HA-tagged recombinant protein expressed by E. coli using anti-HA polyclonal antibody. B, EMSA performed with ${ }^{32} \mathrm{P}$-labeled 21-nucleotide siRNA duplex. Free probe and MBP-GUS-HA were used as negative controls. Increasing concentrations $(0.5,1.0$, and $1.5 \mu \mathrm{g}$ ) of affinity-purified MBP-fused recombinant proteins were incubated with siRNA duplex, were resolved in 5\% polyacrylamide gel, and were revealed by autoradiography. $\mathrm{F}=$ free probe. 
2013; Lutz et al. 2015). Due to nonavailability of orthotospovirus infectious clone for reverse genetics, it is not easy to analyze the effect of NSs self-interaction on WSMoV infection. Based on our previous study, NSs RSS function is correlated to pathogenicity (Huang et al. 2015). In pathogenicity assays, WT NSs can complement the pathogenicity of TuMV mutant HCPro in N. benthamiana plants and restore the severe symptoms (Fig. 7). This phenomenon corroborates our previous

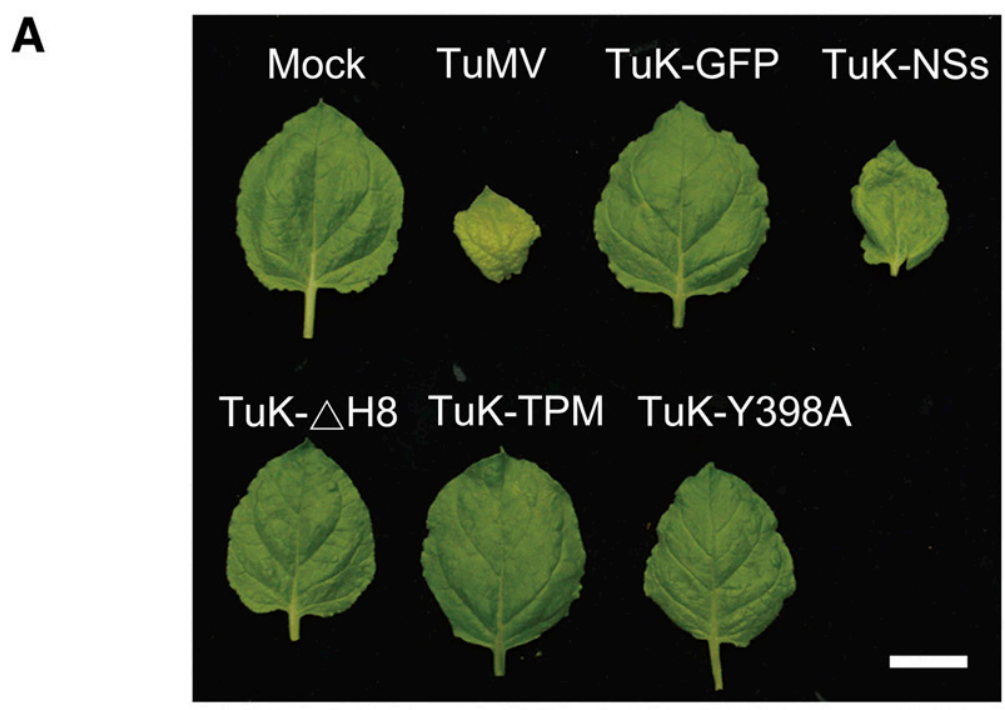

B

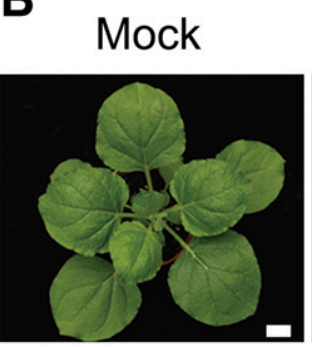

TuMV

TuK-GFP

TuK-NSs

TuK- $\triangle \mathrm{H} 8$
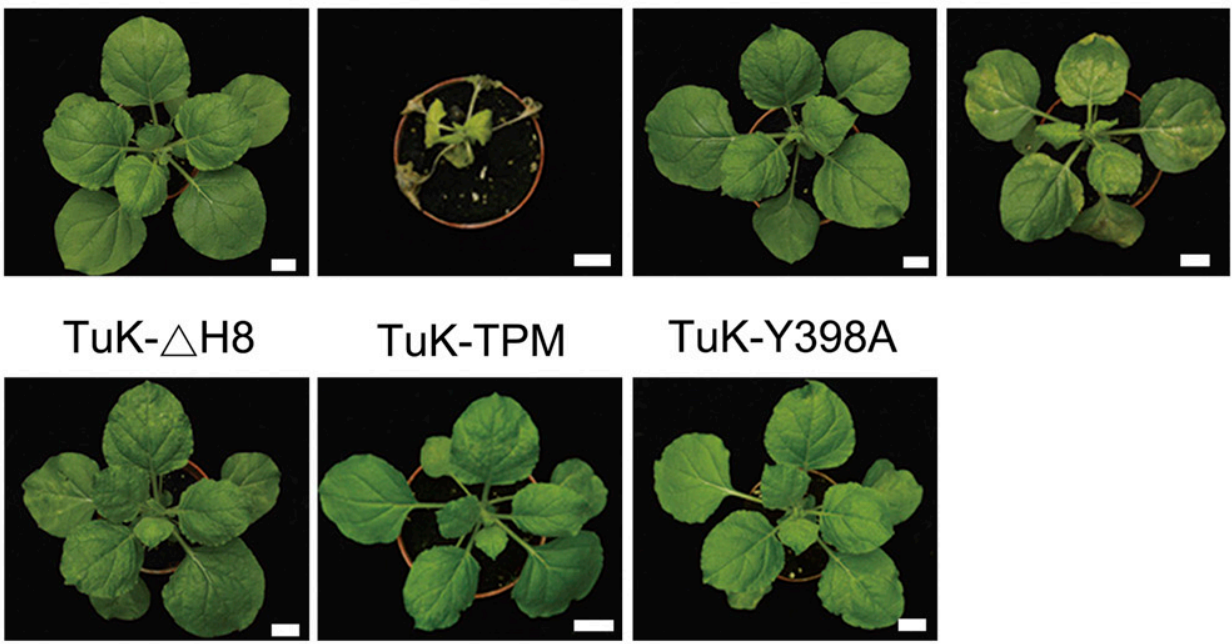

TuK-TPM

TuK-Y398A
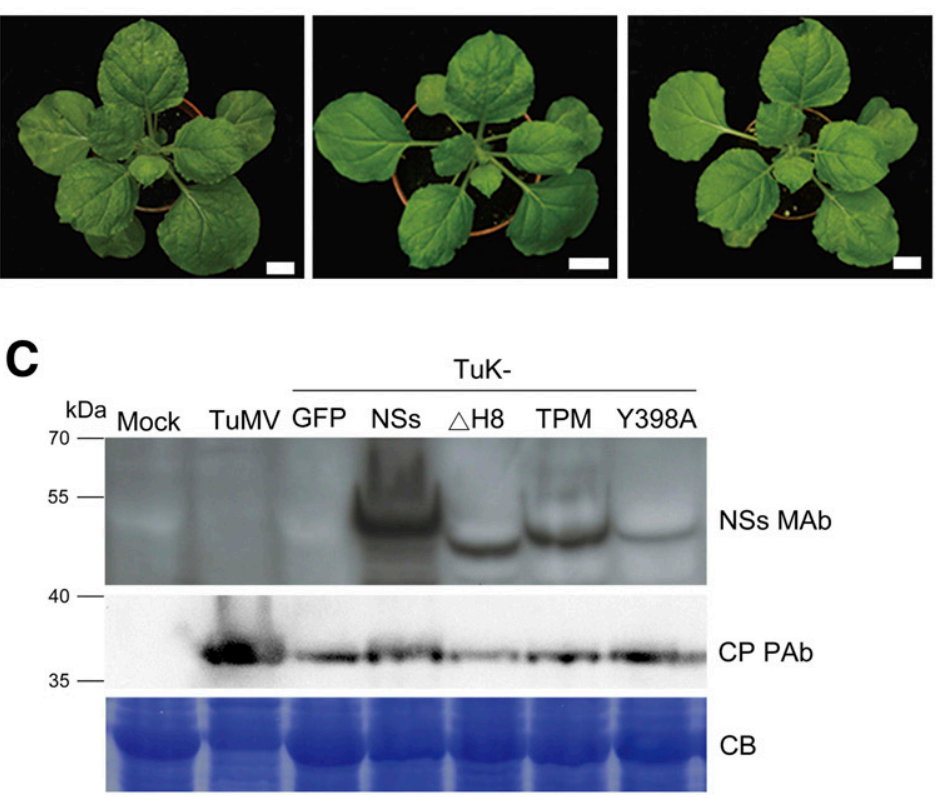

Fig. 7. Pathogenicity analysis of wild-type nonstructural protein S (NSs), NSs proteins with the deletion of C-terminal $\mathrm{H} 8$ helix ( $\Delta \mathrm{H} 8$, amino acids 338 to 359 deleted) or triple point mutation (TPM, Y338A/H350A/F353A within H8 helix) expressed by a heterologous mild vector of turnip mosaic virus (TuMV), TuKGFP. A, Systemic leaves of each inoculated plant and B, symptoms in Nicotiana benthamiana plants inoculated with individual TuMV recombinant viruses expressing wild-type NSs, $\Delta$ H8, TPM, or Y398A protein at 10 days postinoculation (dpi). The Y398A mutant defective in protein stability (Huang et al. 2015) was used as a negative control. C, Detection of mutated NSs proteins expressed by individual TuMV recombinants, at 10 dpi, using anti-NSs monoclonal antibody (Mab) (Chen et al. 2006) or anti-TuMV coat protein polyclonal antibody (CP PAb) (Chen et al. 2007). CB = Coomassie blue-stained total proteins were used as loading controls. Scale bar $=2 \mathrm{~cm}$. 
observation on squash plants (Huang et al. 2015). However, NSs protein restored only the WT TuMV symptoms of leaf curling and mosaic but not the yellowing (Fig. 7). Although, both WSMoV NSs and TuMV HC-Pro proteins are RSSs and have similar molecular weight, the host range and insect vectors of WSMoV and TuMV are different. Thus, NSs or HC-Pro protein may interfere with different miRNAs or host factors, or both, in $N$. benthamiana plants (Kung et al. 2014; Wu et al. 2010). In contrast, the recombinant viruses TuK-Y398A, TuKTPM, and TuK- $\Delta \mathrm{H} 8$ (expressing respectively Y398A, TPM, and $\Delta \mathrm{H} 8$ mutant NSs proteins) did not change the pathogenicity of TuK, as suggested by their mild symptoms.

\section{Application of weaker suppressors to cross-protection.}

Mild strains of potyviruses that heterologously express WSMoV NSs protein mutants may be useful for crossprotection of host plants against the WSMoV severe strain infection. Cross-protection is the phenomenon of protection conferred on plants by infection of one strain of a virus that prevents second infection by a closely related strain of that virus (McKinney 1929). However, cross-protection is highly strain-specific or isolate-specific (Lin et al. 2007; You et al. 2005). Criteria for a suitable mild strain for cross-protection include possession of an inefficient suppressor, induction of mild symptoms, long-term stability, and a zigzag accumulation pattern in host plants (Kung et al. 2014). A previous report showed that potato virus $\mathrm{X}$ carrying a tobacco mosaic virus $\mathrm{CP}$ gene can protect $N$. benthamiana plants against tobacco mosaic tobamovirus (Culver 1996). The attenuated TuK-GFP with a R182K mutation in HC-Pro can be used as cross-protectant, since it fits the criteria as a useful mild strain. Thus, by inserting individual NSs mutated genes into the TuMV mild strain, we speculate that the recombinant viruses can confer protection against both WSMoV and TuMV because a mild strain that triggered RNA silencing in host plants can protect the host in a sequence-homology dependent way (Kung et al. 2014; Lin et al. 2007). Our preliminary result revealed that the TuK-TPM or TuK- $\Delta \mathrm{H} 8$-infected $N$. benthamina plants showed delay in symptom development after challenge inoculation with WSMoV, as compared with TuK-GFP-infected plants (data not shown). There are many factors affecting the cross-protection efficiency, e.g., dosage of the challenged virus, plant condition, time of challenge inculcation. By inserting a heterologous gene of other species of plant viruses, cross-protection against two viruses in different genera can be achieved. This may serve as an effective tool to prevent mixed infection of two different viruses for particular crops. However, further cross-protection experiments need to be conducted to support our idea.

\section{MATERIALS AND METHODS}

\section{Source of viruses and plants.}

The isolate of WSMoV was collected from the leaf tissue of a diseased watermelon plant in Changhua, Taiwan (Yeh and Chang 1995; Yeh et al. 1992). TuMV YC5 isolate was collected from a plant of calla lily (Zantedeschia sp.) cv. Black Magic in Taiwan (Chen et al. 2003). A full length of a complementary DNA infectious clone of TuMV-YC5, designated p35S-TuMVYC5, was constructed and a GFP gene was in frame-inserted between the $\mathrm{NIb}$ and $\mathrm{CP}$ gene regions to generate the recombinant virus TuMV-YC5GFP (Chen et al. 2007). TuMVYC5GFP was used as a backbone to generate a mild mutant virus, TuK-GFP, by introducing and arginine to lysine mutation at the FRNK motif of the HC-Pro gene (Kung et al. 2014). The TuK-GFP induced mild mottling in inoculated leaves and recovery in systemic leaves of $N$. benthamiana plants. In this study, $N$. benthamiana plants were used for analyzing RSS ability and BiFC, pathogenicity, and transient protein stability assays. The plants were grown and maintained in a temperaturecontrolled greenhouse at $25 \pm 3^{\circ} \mathrm{C}$.

\section{Deletion of different parts}

\section{of the NSs ORF for analyzing self-interaction.}

The possible regions of WSMoV NSs protein for selfinteraction were analyzed by YTH analysis, in-vitro co-IP, and $\mathrm{BiFC}$ assay. The following deleted NSs constructs were designed according to the conservation of protein secondary structure (Fig. 1A), using POLYVIEW 2D. The WNSs gene was amplified from the above described WSMoV isolate and was cloned into pENTR vector. The pENTR/WNSs and pENTR/WNSs-nonstop (without stop codon at the end of the NSs protein C-terminus), which contained full-length WSMoV NSs gene, donor vectors were cloned previously (Huang et al. 2015).

The secondary structural analysis of WSMoV NSs protein sequence predicted ten $\alpha$-helices in the protein (Fig. 1A). Based on the sequences of these $\alpha$-helices, primers for the deletion of each $\alpha$-helix by PCR were designed (Table 1 ). The NSs- $\Delta$ C (nucleotides [nt] 645 to 1,320 deleted) fragment was amplified by PCR from $p E N T R / W N S s-n o n s t o p$ with primers P-caccWNSs and N-WNSs- $\Delta$ C. The fragment was cloned in $\mathrm{pENTR/D}$ to generate $\mathrm{pENTR} / \Delta \mathrm{C}$. The strategy for construction of

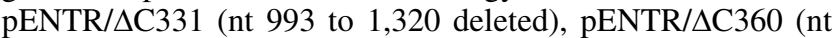
1,080 to 1,320 deleted), $\mathrm{pENTR} / \Delta \mathrm{C} 407$ (nt 1,221 to 1,320 deleted), pENTR/ $\Delta \mathrm{N}$ (nt 1 to 642 deleted), pENTR/ $\triangle \mathrm{N} 111$ (nt 1 to 333 deleted), pENTR/ $\Delta \mathrm{N} 158$ (nt 1 to 474 deleted), and pENTR/AN193 (nt 1 to 579 deleted) were similar to that of $\mathrm{pENTR} / \Delta \mathrm{C}$, except for the use of primer pairs of PcaccWNSs/N-WNSs- $\Delta$ C331, P-caccWNSs/N-WNSs- $\Delta$ C360, P-caccWNSs/N-WNSs- $\Delta$ C407，P-WNSs- $\Delta N / N-W N S s-n o n s t o p$, P-WNSs- $\Delta$ N111/N-WNSs-nonstop, P-WNSs- $\Delta$ N158/N-WNSsnonstop, and P-WNSs- $\Delta$ N193/N-WNSs-nonstop, respectively. Then, pENTR constructs were individually transferred to pMALDC-HA, pMAL-DC-Myc, pGAD424-DC, pGBT9-DC (provided by N.-H. Chua at Rockefeller University, New York), pBA-DCMyc-NEYFP and pBA-DC-HA-CEYFP (provided by S.-S. Lin at National Taiwan University, Taipei, Taiwan) by LR Clonase enzyme (Invitrogen, Carlsbad, CA, U.S.A.) to generate the pMALNSs-HA and pMAL-NSs-Myc for co-IP or pull-down assay, pGAD424-NSs and pGBT9-NSs for YTH, pBA-NSs-MycNEYFP and pBA-NSs-HA-CEYFP for BiFC. The other deleted NSs fragments were constructed following the same strategy.

\section{Construction of $\Delta \mathrm{HB}$ deletion mutant and H8 point mutants of NSs for analyzing self-interaction.}

The confidence level of prediction of the H8 helix (aa 338 to 360 ) at the $\mathrm{C}$ terminus is the highest among helices in WSNoV (Fig. 1A). Thus, the deleted aa 338 to 360 (H8) and aa that are charged $(\mathrm{K}, \mathrm{H}$, and $\mathrm{E}$ ) or aromatic ( $\mathrm{Y}$ and $\mathrm{F}$ ) within aa 338 to 360 were selected for analyzing their possible roles in selfinteraction and RSS function. The deleted-aa H8 ( $\Delta 338-360)$ fragment was amplified by overlapping PCR and is described below. The NSs- $\Delta 338-360$-a (aa 1 to 337 , nt 1 to 1,011 ) and NSs- $\Delta 338-360-\mathrm{b}$ (aa 361 to 439 , nt 1,083 to 1,320 ) fragments were amplified from $\mathrm{pBCo}-\mathrm{NSs}$ by PCR with primer pairs $\mathrm{P}$-caccWNSs/N-WNSs- $\Delta \mathrm{H} 8$ and P-WNSs- $\Delta \mathrm{H} 8 / \mathrm{N}-\mathrm{WNSs}-$ nonstop, respectively. The NSs- $\Delta 338-360$ fragment was amplified by overlapping PCR with primer pair P-caccWNSs/N-WNSsnonstop from a mixture template of NSs- $\Delta 338-360$-a (NSs 338) and NSs- $\Delta 338-360-\mathrm{b}$ fragments and, then, was cloned into $\mathrm{pENTR/D}$ to generate $\mathrm{pENTR/WNSs} \Delta \mathrm{H} 8$-nonstop.

Specific single mutations, Y338A, K344A, H350A, F353A, and E359A, and the TPM Y338A/H350A/F353A were generated by the Quik Change XL site-directed mutagenesis kit 
(Stratagene Corp., La Jolla, CA, U.S.A.) on pENTR/WNSsnonstop. Then, the pENTR/WNSs $\Delta$ H8-nonstop was transferred to pBA-DC-Myc-NEYFP, pBA-DC-HA-CEYFP, pGAD424DC, pGBT9-DC, pMAL-DC-HA, and pMAL-DC-Myc (provided by N.-H. Chua, Rockefeller University) by LR Clonase enzyme (Invitrogen) to generate the pBA-NSs $\Delta \mathrm{H} 8$-MycNEYFP, pBA-NSs $\triangle H 8-H A-c Y F P, \quad$ GAD424- NSs $\Delta \mathrm{H} 8$, pGBT9-NSs $\Delta$ H8, pMAL-NSs $\Delta$ H8-HA and pMAL-NSs $\Delta H 8$ Myc, respectively. The charged or aromatic aa of Y338, K344, $\mathrm{H} 350, \mathrm{~F} 353$, and E359 within the H8 helix were also chosen for self-interaction study. The alanine-substitution mutagenesis of these residues were performed following the same strategy to generate each point-mutated NSs gene in individual vectors, pGAD424-NSs and pGBT9-NSs for YTH, pMAL-NSs-HA and pMAL-NSs-Myc for in vitro co-IP assay, pBA-NSs-MycNEYFP and pBA-NSs-HA-CEYFP for BiFC. For pull-down assay, the WT NSs gene was amplified with primer pair P-NSs BamHI/N-NSs SmaI by PCR. The fragment was cloned into the pGEX vector (GE Healthcare, Piscataway, NJ, U.S.A.) to generate pGEX-NSs.

\section{Construction of $\Delta \mathrm{H8}$ and point mutations of NSs for RSS function.}

The NSs- $\Delta \mathrm{H} 8$ fragment was amplified by PCR from pENTR/WNSs- $\Delta$ H8-nonstop with primers P-caccWNSs and $\mathrm{N}-\mathrm{WNSs}$. The fragments were cloned in $\mathrm{pENTR/D}$ to generate $\mathrm{pENTR/WNSs} \Delta \mathrm{H} 8$. Then, the pENTR/WNSs $\Delta \mathrm{H} 8$ was transferred to pBCo-DC-Myc (Wu et al. 2010) by LR Clonase enzyme to generate the $\mathrm{pBCo}-\Delta \mathrm{H} 8$. The other charged or aromatic aas within aa 338 to 360 , Y338A, K344A, H350A, F353A, E359A, or Y338A/ H350A/F353A (TPM) were single- or triple-point mutated in NSs fragments, following the same strategy to generate each point mutation of NSs gene in pBCo vector, then, were transformed to A. tumefaciens ABI for RSS assay.

\section{Co-IP and pull-down assay.}

Total protein of E. coli (strain BL21) expressing individual protein expression constructs (pMAL or pGEX) was extracted by sonication in the column buffer (20 mM Tris, pH 7.4, $200 \mathrm{mM}$ $\mathrm{NaCl}, 1 \mathrm{mM}$ dithiothreitol [DTT], and $1 \times$ protease inhibitor cocktail [Roche, Indianapolis, IN, U.S.A.]) or phosphate buffered saline. The MBP- or GST-fused proteins were purified with amylose resin (New England Biolabs, Ipswich, MA, U.S.A.) or GST agarose resin (Thermo Scientific, Chicago), respectively. Two purified recombinant proteins ( $2 \mu \mathrm{g}$ each) were mixed with binding buffer $(50 \mathrm{mM}$ Tris, $\mathrm{pH} 7.5,100 \mathrm{mM} \mathrm{NaCl}, 0.25 \%$ Triton $\mathrm{X}-100,0.5 \mathrm{M} \beta$-mercaptoethanol and $1 \times$ protease inhibitor cocktail) and were incubated at room temperature for $1 \mathrm{~h}$, followed by the addition of polyclonal antibody HA sc-805 (Santa Cruz Biotechnology, Santa Cruz, CA, U.S.A.) or glutathione agarose resin, respectively, and were gently rotated by ERM2L-1.5 Intelli Mixer with $30 \mathrm{rpm}$ (Violet BioScience, Taipei, Taiwan) at room temperature for $1 \mathrm{~h}$. Later, protein A Mag Sepharose Xtra was added (GE Healthcare) and the sample was rotated in a similar way at room temperature for an additional $1 \mathrm{~h}$ for the co-IP assay. After washing five times with the binding buffer, sample was then dissolved in $3 \times$ protein sample buffer (3\% sodium dodecyl sulfate (SDS), $30 \%$ glycerol, $0.01 \%$ bromophenol blue, and $15 \% \beta$-mercaptoethanol). The immunoprecipitated, pulled-down proteins were analyzed by Western blotting as described below.

Table 1. Oligonucleotide primers used in this study

\begin{tabular}{|c|c|c|}
\hline Name & Sequence $\left(5^{\prime} \text { to } 3^{\prime}\right)^{\mathbf{a}}$ & Polarity ${ }^{\mathrm{b}}$ \\
\hline \multicolumn{3}{|l|}{ Deletion } \\
\hline P-caccWNSs & caccATGTCTACTGCAAAGAAT & + \\
\hline N-WNSs-nonstop & TTCTGCTTTCACAACAAAGTG & - \\
\hline N-WNSs & TTATTCTGCTTTCACAACAA & \\
\hline N-WNSs- $\Delta \mathrm{C}$ & TAGCAATCTGTTGGTAGGGAC & - \\
\hline N-WNSs- $\Delta \mathrm{C} 331$ & ATCAACAAGACCTACTCTTGC & - \\
\hline N-WNSs- $\Delta \mathrm{C} 360$ & TTCAGATAAATTGATAGCAAAC & - \\
\hline N-WNSs- $\Delta$ C407 & AACCTCGAGAGTCTTTGAGAG & - \\
\hline P-WNSs- $\Delta \mathrm{N}$ & сасcTCTACATCAACAGTCAAAGG & + \\
\hline P-WNSs- $\Delta \mathrm{N} 111$ & caccatgCACAATCAAATCTTTAATC & + \\
\hline P-WNSs- $\Delta$ N158 & caccatgAAGAATAATTTCTATATAG & + \\
\hline P-WNSs- $\Delta$ N193 & caccatgAAGATCTTGTCAGTTAAGC & + \\
\hline P-WNSs- $\Delta \mathrm{H} 8$ & AGTGATCCCAATATTCAAAAGCCAGTCATAGTGTTC & + \\
\hline N-WNSs- $\Delta \mathrm{H} 8$ & GACTGGCTTTTGAATATTGGGATCACTATCACAGAAATC & - \\
\hline \multicolumn{3}{|l|}{ Point-mutation } \\
\hline P-Y338A & GATTTCTGTGATAGTGATCCCAATGCCAATCAATTGATTGTCAAGAATC & + \\
\hline N-Y338A & GATTCTTGACAATCAATTGATTGGCATTGGGATCACTATCACAGAAATC & - \\
\hline P-K344A & CAATTACAATCAATTGATTGTCGCGAATCTGTTAAGTGTCCATAC & + \\
\hline N-K344A & GTATGGACACTTAACAGATTCGCGACAATCAATTGATTGTAATTG & - \\
\hline P-H350A & GTCAAGAATCTGTTAAGTGTCGCTACTCAGTTTGCTATCAATTTATC & + \\
\hline $\mathrm{N}-\mathrm{H} 350 \mathrm{~A}$ & GATAAATTGATAGCAAACTGAGTAGCGACACTTAACAGATTCTTGAC & - \\
\hline P-F353A & CTGTTAAGTGTCCATACTCAGGCTGCTATCAATTTATCTGAAG & + \\
\hline N-F353A & CTTCAGATAAATTGATAGCAGCCTGAGTATGGACACTTAACAG & - \\
\hline P-E359A & CAGTTTGCTATCAATTTATCTGCAGTTATTCAAAAGCCAGTCATAG & + \\
\hline N-E359A & CTATGACTGGCTTTTGAATAACTGCAGATAAATTGATAGCAAACTG & - \\
\hline \multicolumn{3}{|l|}{ Pathogenicity assay } \\
\hline P-NcoI WNSs & catgccATGGCAATGTCTACTGCAAAG & + \\
\hline N-NheI WNSs & gctagcTTCTGCTTTCACAACAAAG & - \\
\hline P-Actin & CAGCAAAGACCAGCTCATCC & \\
\hline N-Actin & AGCAGCTTCCATTCCGATCA & \\
\hline P-WNSs & GCTGCAAGTTCACAATGCAC & + \\
\hline N-WNSs & GCACTCATCCAAACACCATCC & - \\
\hline
\end{tabular}

a Bolded bases represent mutated nucleotides and lower-case letters denote nonviral sequences, e.g., restriction enzyme site or sequences for cloning.

${ }^{\mathrm{b}}$ Polarity to watermelon silver mottle virus nonstructural protein S (NSs) coding sequence. 


\section{YTH assay.}

To analyze self-interaction of NSs mutants by YTH, WT NSs or individually mutated NSs constructs in the plasmids of pGBT9 or pGAD424 were cotransformed into Saccharomyces cerevisiae AH109 (Clontech, Palo Alto, CA, U.S.A.). Transformants were grown at $30^{\circ} \mathrm{C}$ for 2 days on synthetic defined (SD) medium lacking leucine (Leu) and tryptophan (Trp), and a single colony was picked from plate to liquid SD medium lacking Leu and Trp to culture at $30^{\circ} \mathrm{C}$, overnight. Then, liquid yeast cell culture was transferred to the SD medium lacking histidine, Leu, and Trp with different concentrations of 3aminotriazole to analyze the strength of interaction.

\section{Agroinfiltration.}

RSS and BiFC assays of deleted or point-mutated NSs protein were performed on $N$. benthamiana plants by transient expression with agroinflitration. An overnight culture of A. tumefaciens ABI containing individual deleted or pointmutated NSs ORFs was diluted 50-fold in Luria Bertani medium with $10 \mathrm{mM}$ MES (4-morpholineethanesulfonic acid) and $0.5 \mathrm{mM}$ aectosyringon. The culture was grown at $28^{\circ} \mathrm{C}$ to an $\mathrm{OD}_{600}$ of 1.0. The cells were resuspended in $0.01 \mathrm{M} \mathrm{MgCl}_{2}$ with $1 \mathrm{mM}$ aectosyringon and were incubated at room temperature for $3 \mathrm{~h}$ before agroinfiltration performed as previously described (English et al. 1997).

\section{BiFC.}

A mixed Agrobacterium suspension from individual cultures carrying individual WT or mutated NSs fused with the NEYFP or CEYFP constructs was agroinfitrated into leaf tissues of $N$. benthamiana plants, using a syringe without a needle. At 2 dpa, the infiltrated leaf tissues were examined by confocal microscopy. The Fluoview FV1000 confocal laser scanning microscopy (Olympus, Tokyo) was used to examine the EYFP expression in agroinfiltrated leaves.

\section{RSS assay.}

The RSS assay was performed as described previously (Huang et al. 2015). Briefly, the construct pBA-GFP or pBA-GFi carrying a full-length GFP ORF or partial hairpin GFP ORF was used to express or induce GFP silencing in $N$. benthamiana plants, respectively. RSS activity assay in plant was performed by coinfiltrating a mixture containing mutated NSs construct, GFP expresser, and GFP silencer. A mixture containing the EV combined with GFP expresser and silencer constructs was used as the negative control. Four days after coinfiltration, RSS activities were recorded by observation of GFP expression. Visual observation of GFP fluorescence in the infiltrated leaves was performed using a Nikon D7000 digital single lens camera (Nikon, Tokyo) under blue LED light (Chalfie 2009).

\section{Northern and Western blotting.}

WSMoV NSs RNA and protein accumulation after agroinfiltration or virus infection was analyzed by Northern and Western blotting, respectively. Total RNA extracted from $0.05 \mathrm{~g}$ of infiltrated or inoculated leaves by TRizol reagent (Invitrogen) was used for Northern hybridization analysis. Genespecific $\alpha-{ }^{32} \mathrm{P}-$ labeled probes were synthesized by Prime-it II random primer labeling kit (Stratagene Corp.) using the WSMoV NSs, GFP, or 18S rRNA coding region as a template.

Total soluble proteins from $0.05 \mathrm{~g}$ of infiltrated leaves were extracted by grinding the tissues in $3 \times$ protein sample buffer. The samples were incubated at $100^{\circ} \mathrm{C}$ for $5 \mathrm{~min}$ and, then, the supernatant was collected after centrifugation $(8,000 \times g, 3$ $\mathrm{min})$. The proteins were resolved in a $12 \%$ SDS-polyacrylamide gel and were transferred to Polyscreen polyvinylidene fluoride (PerkinElmer, Waltham, MA, U.S.A.) membrane. Membranes were reacted with individual antibodies, including MAb to WSMoV NSs (Chen et al. 2006) and MAb to c-Myc sc-40 (Santa Cruz Biotechnology) and polyclonal antibody (PAb) to GFP (Hsu et al. 2004) and PAb to TuMV CP (Chen et al. 2007). All antibodies were diluted 5,000-fold, except WSMoV NSs Mab, which was diluted 10,000-fold. Membrane was stained with Coomassie brilliant blue R250 and the amount of the large subunit of RuBisCO (ribulose-1,5-bisphosphate carboxylase/ oxygenase) was used as a loading control.

\section{EMSA.}

Purified recombinant MBP-fused WT NSs and individual mutated NSs proteins were tested for siRNA binding. Synthetic siRNA duplex with 2 nt of $3^{\prime}$ overhanging (sense: 5' - GCA GCA CGA CUU CUU CAA GTT - $3^{\prime}$ 'antisense: 5' - CUU GAA GAA GUC GUG CUG CTT -3') (MDBio, Taipei, Taiwan) were radioactively labeled with $\gamma_{-}{ }^{32} \mathrm{P}$ ATP by T4 polynucleotide kinase (New England Biolabs) and were used as a probe for proteinRNA binding assay. After end-labeling, siRNA was purified with Sephadex G-25 column (Roche). The labeled siRNA (final concentration of $1 \mathrm{nM}$ ) was incubated with purified protein (concentration varied from $0.5,1.0$, and $1.5 \mu \mathrm{g}$ ) in the binding buffer (20 mM HEPES, pH 8.0, $50 \mathrm{mM} \mathrm{KCl,} 1 \mathrm{mM}$ DTT, and 5\% [vol/vol] glycerol) in a total volume of $25 \mu \mathrm{l}$ and were incubated at room temperature for $25 \mathrm{~min}$. The binding mixture was examined by $6 \%$ (vol/vol) nondenaturing polyacrylamide gel electrophoresis at $4^{\circ} \mathrm{C}(150 \mathrm{~V}$ for $1 \mathrm{~h})$, and then, the gel was dried and mounted on X-ray film (Amersham Hyperfilm MP, GE Healthcare Life Science, Hertfordshire, U.K.) at $-80^{\circ} \mathrm{C}$.

\section{Construction and analysis of TuMV recombinant virus for pathogenicity.}

In order to study the pathogenicity of the WT NSs protein and the mutated NSs proteins, the GFP reading frame of a mild strain construct of TuK-GFP (Kung et al. 2014) was replaced by WT NSs ORF and its mutants. First, the WT NSs coding region was amplified by PCR, with forward primer P-NcoI WNSs and reverse primer N-NheI WNSs, which contains a NcoI restriction site added at the $5^{\prime}$ end and a NheI restriction site added at the $3^{\prime}$ end, from pENTR-WNSs. The PCR product was digested with the corresponding restriction enzymes. Subsequently, the TuKGFP virus was used as a backbone to construct recombinant virus TuK-NSs, by replacing the GFP ORF with the WT NSs ORF. The recombinant viruses of individual mutated NSs ORFs, TuKNSs- $\Delta$ nss, TuK-NSs-H113A, TuK-NSs-Y398A, TuK-NSs-TPM, and TuK-NSs- $\Delta \mathrm{H} 8$ were constructed using the same strategy.

To assay the pathogenicity of NSs protein and its mutants, the constructs of recombinant viruses carrying individual ORFs were introduced into $N$. benthamiana plants. Each plasmid $(1.5 \mu \mathrm{g})$ for generating individual recombinant viruses was introduced, by rubbing with a pestle, into $N$. benthamiana leaves dusted with 600-mesh Carborundum. Symptomatic upper leaves of $N$. benthamiana plants were harvested and ground in phosphate buffer $\left(10 \mathrm{mM} \mathrm{K}_{2} \mathrm{HPO}_{4}, 10 \mathrm{mM} \mathrm{KH}_{2} \mathrm{PO}_{4}, \mathrm{pH} 7.0\right)$ at a 1:20 (wt/vol) dilution. The extracted recombinant viruses were further introduced to $N$. benthamiana plants for observation of symptom development.

\section{ACKNOWLEDGMENTS}

We are grateful to S.-H. Chang for helping the confocal microscopy experiments.

\section{AUTHOR-RECOMMENDED INTERNET RESOURCES}

International Committee on Taxonomy of Viruses (ICTV) 10th Report: https://talk.ictvonline.org/ictv-reports/ictv_online_report POLYVIEW 2D software: http://polyview.cchmc.org 


\section{LITERATURE CITED}

Aguilar, E., Almendral, D., Allende, L., Pacheco, R., Chung, B. N., Canto, T., and Tenllado, F. 2015. The $\mathrm{P} 25$ protein of potato virus $\mathrm{X}$ (PVX) is the main pathogenicity determinant responsible for systemic necrosis in PVX-associated synergisms. J. Virol. 89:2090-2103.

Azevedo, J., Garcia, D., Pontier, D., Ohnesorge, S., Yu, A., Garcia, S., Braun, L., Bergdoll, M., Hakimi, M. A., Lagrange, T., and Voinnet, O. 2010. Argonaute quenching and global changes in Dicer homeostasis caused by a pathogen-encoded GW repeat protein. Genes Dev. 24: 904-915.

Azzarito, V., Long, K., Murphy, N. S., and Wilson, A. J. 2013. Inhibition of $\alpha$-helix-mediated protein-protein interactions using designed molecules. Nat. Chem. 5:161-173.

Bhushan, L., Abraham, A., Choudhury, N. R., Rana, V. S., Mukherjee, S. K., and Savithri, H. S. 2015. Demonstration of helicase activity in the nonstructural protein, NSs, of the negative-sense RNA virus, groundnut bud necrosis virus. Arch. Virol. 160:959-967.

Bucher, E., Sijen, T., De Haan, P., Goldbach, R., and Prins, M. 2003. Negative-strand tospoviruses and tenuiviruses carry a gene for a suppressor of gene silencing at analogous genomic positions. J. Virol. 77:1329-1336.

Cañizares, M. C., Lozano-Durán, R., Canto, T., Bejarano, E. R., Bisaro, D. M., Navas-Castillo, J., and Moriones, E. 2013. Effects of the crinivirus coat protein-interacting plant protein SAHH on posttranscriptional RNA silencing and its suppression. Mol. Plant-Microbe Interact. 26:1004-1015.

Chalfie, M. 2009. GFP: Lighting up life. Proc. Natl. Acad. Sci. U.S.A. 106 $10073-10080$

Chao, J. A., Lee, J. H., Chapados, B. R., Debler, E. W., Schneemann, A., and Williamson, J. R. 2005. Dual modes of RNA-silencing suppression by Flock House virus protein B2. Nat. Struct. Mol. Biol. 12: 952-957.

Chen, C. C., Chao, C. H., Chen, C. C., Yeh, S. D., Tsai, H. T., and Chang, C. A. 2003. Identification of Turnip mosaic virus isolates causing yellow stripe and spot on calla lily. Plant Dis. 87:901-905.

Chen, C. C., Chen, T. C., Raja, J. A., Chang, C. A., Chen, L. W., Lin, S. S., and Yeh, S. D. 2007. Effectiveness and stability of heterologous proteins expressed in plants by Turnip mosaic virus vector at five different insertion sites. Virus Res. 130:210-227.

Chen, T. C., Huang, C. W., Kuo, Y. W., Liu, F. L., Yuan, C. H., Hsu, H. T., and Yeh, S. D. 2006. Identification of common epitopes on a conserved region of NSs proteins among tospoviruses of Watermelon silver mottle virus serogroup. Phytopathology 96:1296-1304.

Chu, F. H., Chao, C. H., Chung, M. H., Chen, C. C., and Yeh, S. D. 2001. Completion of the genome sequence of Watermelon silver mottle virus and utilization of degenerate primers for detecting tospoviruses in five serogroups. Phytopathology 91:361-368.

Chu, F. H., and Yeh, S. D. 1998. Comparison of ambisense m RNA of watermelon silver mottle virus with other tospoviruses. Phytopathology 88:351-358.

Collins, R. E., and Cheng, X. 2005. Structural domains in RNAi. FEBS Lett. 579:5841-5849.

Csorba, T., Lózsa, R., Hutvágner, G., and Burgyán, J. 2010. Polerovirus protein P0 prevents the assembly of small RNA-containing RISC complexes and leads to degradation of ARGONAUTE1. Plant J. 62: 463-472.

Csorba, T., Pantaleo, V., and Burgyán, J. 2009. RNA silencing: An antiviral mechanism. Adv. Virus Res. 75:35-71, 230.

Culver, J. N. 1996. Tobamovirus cross protection using a potexvirus vector Virology 226:228-235.

Curaba, J., and Chen, X. 2008. Biochemical activities of Arabidopsis RNAdependent RNA polymerase 6. J. Biol. Chem. 283:3059-3066.

Danielson, D. C., and Pezacki, J. P. 2013. Studying the RNA silencing pathway with the p19 protein. FEBS Lett. 587:1198-1205.

de Haan, P., de Avila, A. C., Kormelink, R., Westerbroek, A., Gielen, J. J., Peters, D., and Goldbach, R. 1992. The nucleotide sequence of the $S$ RNA of Impatiens necrotic spot virus, a novel tospovirus. FEBS Lett. 306:27-32.

de Haan, P., Kormelink, R., de Oliveira Resende, R., van Poelwijk, F., Peters, D., and Goldbach, R. 1991. Tomato spotted wilt virus L RNA encodes a putative RNA polymerase. J. Gen. Virol. 72:2207-2216.

de Ronde, D., Butterbach, P., Lohuis, D., Hedil, M., van Lent, J. W., and Kormelink, R. 2013. Tsw gene-based resistance is triggered by a functional RNA silencing suppressor protein of the Tomato spotted wilt virus. Mol. Plant Pathol. 14:405-415.

de Ronde, D., Pasquier, A., Ying, S., Butterbach, P., Lohuis, D., and Kormelink, R. 2014. Analysis of Tomato spotted wilt virus NSs protein indicates the importance of the N-terminal domain for avirulence and RNA silencing suppression. Mol. Plant Pathol. 15:185-195.

English, J., Davenport, G., Elmayan, T., Vaucheret, H., and Baulcombe, D. 1997. Requirement of sense transcription for homology-dependent virus resistance and trans-inactivation. Plant J. 12:597-603.

Fukunaga, R., and Doudna, J. A. 2009. dsRNA with $5^{\prime}$ overhangs contributes to endogenous and antiviral RNA silencing pathways in plants. EMBO J. 28:545-555.

Garcia, S., Billecocq, A., Crance, J. M., Prins, M., Garin, D., and Bouloy, M. 2006. Viral suppressors of RNA interference impair RNA silencing induced by a Semliki Forest virus replicon in tick cells. J. Gen. Virol. 87: 1985-1989.

Goswami, S., Sahana, N., Pandey, V., Doblas, P., Jain, R. K., Palukaitis, P., Canto, T., and Praveen, S. 2012. Interference in plant defense and development by non-structural protein NSs of groundnut bud necrosis virus. Virus Res. 163:368-373.

Guo, H., Song, X., Xie, C., Huo, Y., Zhang, F., Chen, X., Geng, Y., and Fang, R. 2013. Rice yellow stunt rhabdovirus protein 6 suppresses systemic RNA silencing by blocking RDR6-mediated secondary siRNA synthesis. Mol. Plant-Microbe Interact. 26:927-936.

Haas, G., Azevedo, J., Moissiard, G., Geldreich, A., Himber, C., Bureau, M., Fukuhara, T., Keller, M., and Voinnet, O. 2008. Nuclear import of CaMV P6 is required for infection and suppression of the RNA silencing factor DRB4. EMBO J. 27:2102-2112.

Hafrén, A., Macia, J. L., Love, A. J., Milner, J. J., Drucker, M., and Hofius, D. 2017. Selective autophagy limits cauliflower mosaic virus infection by NBR1-mediated targeting of viral capsid protein and particles. Proc. Natl. Acad. Sci. U.S.A. 114:E2026-E2035

Hsu, C. H., Lin, S. S., Liu, F. L., Su, W. C., and Yeh, S. D. 2004. Oral administration of a mite allergen expressed by zucchini yellow mosaic virus in cucurbit species downregulates allergen-induced airway inflammation and IgE synthesis. J. Allergy Clin. Immunol. 113:1079-1085.

Huang, C. H., Hsiao, W. R., Huang, C. W., Chen, K. C., Lin, S. S., Chen, T. C., Raja, J. A., Wu, H. W., and Yeh, S. D. 2015. Two novel motifs of Watermelon silver mottle virus NSs protein are responsible for RNA silencing suppression and pathogenicity. PLoS One 10:e0126161.

Hutvagner, G., and Simard, M. J. 2008. Argonaute proteins: Key players in RNA silencing. Nat. Rev. Mol. Cell Biol. 9:22-32.

Kormelink, R., Kitajima, E. W., De Haan, P., Zuidema, D., Peters, D., and Goldbach, R. 1991. The nonstructural protein (NSs) encoded by the ambisense S RNA segment of tomato spotted wilt virus is associated with fibrous structures in infected plant cells. Virology 181:459-468.

Kormelink, R., Storms, M., Van Lent, J., Peters, D., and Goldbach, R. 1994 Expression and subcellular location of the NSM protein of tomato spotted wilt virus (TSWV), a putative viral movement protein. Virology 200:56-65.

Kung, Y. J., Lin, P. C., Yeh, S. D., Hong, S. F., Chua, N. H., Liu, L. Y., Lin, C. P., Huang, Y. H., Wu, H. W., Chen, C. C., and Lin, S. S. 2014. Genetic analyses of the FRNK motif function of Turnip mosaic virus uncover multiple and potentially interactive pathways of cross-protection. Mol Plant-Microbe Interact. 27:944-955.

Lakatos, L., Csorba, T., Pantaleo, V., Chapman, E. J., Carrington, J. C., Liu, Y. P., Dolja, V. V., Calvino, L. F., López-Moya, J. J., and Burgyán, J. 2006. Small RNA binding is a common strategy to suppress RNA silencing by several viral suppressors. EMBO J. 25:2768-2780.

Lin, S. S., Wu, H. W., Jan, F. J., Hou, R. F., and Yeh, S. D. 2007. Modifications of the helper component-protease of Zucchini yellow mosaic virus for generation of attenuated mutants for cross protection against severe infection. Phytopathology 97:287-296.

Lokesh, B., Rashmi, P. R., Amruta, B. S., Srisathiyanarayanan, D., Murthy, M. R., and Savithri, H. S. 2010. NSs encoded by groundnut bud necrosis virus is a bifunctional enzyme. PLoS One 5:e9757.

Lutz, L., Okenka, G., Schoelz, J., and Leisner, S. 2015. Mutations within A 35 amino acid region of P6 influence self-association, inclusion body formation, and Caulimovirus infectivity. Virology 476:26-36.

Margaria, P., Bosco, L., Vallino, M., Ciuffo, M., Mautino, G. C., Tavella, L., and Turina, M. 2014. The NSs protein of Tomato spotted wilt virus is required for persistent infection and transmission by Frankliniella occidentalis. J. Virol. 88:5788-5802.

McKinney, H. H. 1929. Mosaic diseases in the Canary Islands, West Africa, and Gibraltar. J. Agric. Res. 39:577-578.

Mérai, Z., Kerényi, Z., Kertész, S., Magna, M., Lakatos, L., and Silhavy, D. 2006. Double-stranded RNA binding may be a general plant RNA viral strategy to suppress RNA silencing. J. Virol. 80:5747-5756.

Moshe, A., Belausov, E., Niehl, A., Heinlein, M., Czosnek, H., and Gorovits, R. 2015. The Tomato yellow leaf curl virus V2 protein forms aggregates depending on the cytoskeleton integrity and binds viral genomic DNA. Sci. Rep. 5:9967. 
Mourrain, P., Béclin, C., Elmayan, T., Feuerbach, F., Godon, C., Morel, J. B., Jouette, D., Lacombe, A. M., Nikic, S., Picault, N., Rémoué, K., Sanial, M., Vo, T. A., and Vaucheret, H. 2000. Arabidopsis SGS2 and $S G S 3$ genes are required for posttranscriptional gene silencing and natural virus resistance. Cell 101:533-542.

Nykänen, A., Haley, B., and Zamore, P. D. 2001. ATP requirements and small interfering RNA structure in the RNA interference pathway. Cell 107:309-321.

Okano, Y., Senshu, H., Hashimoto, M., Neriya, Y., Netsu, O., Minato, N., Yoshida, T., Maejima, K., Oshima, K., Komatsu, K., Yamaji, Y., and Namba, S. 2014. In planta recognition of a double-stranded RNA synthesis protein complex by a potexviral RNA silencing suppressor. Plant Cell 26:2168-2183.

Oliveira, V. C., Bartasson, L., de Castro, M. E., Corrêa, J. R., Ribeiro, B. M., and Resende, R. O. 2011. A silencing suppressor protein (NSs) of a tospovirus enhances baculovirus replication in permissive and semipermissive insect cell lines. Virus Res. 155:259-267.

Peragine, A., Yoshikawa, M., Wu, G., Albrecht, H. L., and Poethig, R. S. 2004. SGS3 and SGS2/SDE1/RDR6 are required for juvenile development and the production of trans-acting siRNAs in Arabidopsis. Genes Dev. 18:2368-2379.

Qiu, W., Park, J. W., and Scholthof, H. B. 2002. Tombusvirus P19-mediated suppression of virus-induced gene silencing is controlled by genetic and dosage features that influence pathogenicity. Mol. Plant-Microbe Interact. 15:269-280.

Reavy, B., Dawson, S., Canto, T., and MacFarlane, S. A. 2004. Heterologous expression of plant virus genes that suppress posttranscriptional gene silencing results in suppression of RNA interference in Drosophila cells. BMC Biotechnol. 4:18.

Riedel, D., Lesemann, D. E., and Maiss, E. 1998. Ultrastructural localization of nonstructural and coat proteins of 19 potyviruses using antisera to bacterially expressed proteins of plum pox potyvirus. Arch. Virol. 143:2133-2158.

Ruiz-Ferrer, V., Boskovic, J., Alfonso, C., Rivas, G., Llorca, O., LópezAbella, D., and López-Moya, J. J. 2005. Structural analysis of tobacco etch potyvirus HC-pro oligomers involved in aphid transmission. J. Virol. 79:3758-3765.

Ruiz-Ferrer, V., and Voinnet, O. 2009. Roles of plant small RNAs in biotic stress responses. Annu. Rev. Plant Biol. 60:485-510.

Sahana, N., Kaur, H., Jain, R. K., Palukaitis, P., Canto, T., and Praveen, S. 2014. The asparagine residue in the FRNK box of potyviral helpercomponent protease is critical for its small RNA binding and subcellular localization. J. Gen. Virol. 95:1167-1177.

Schnettler, E., Hemmes, H., Huismann, R., Goldbach, R., Prins, M., and Kormelink, R. 2010. Diverging affinity of tospovirus RNA silencing suppressor proteins, NSs, for various RNA duplex molecules. J. Virol. 84:11542-11554.

Seo, J. K., Kwon, S. J., and Rao, A. L. 2012. Molecular dissection of Flock house virus protein $\mathrm{B} 2$ reveals that electrostatic interactions between $\mathrm{N}$ terminal domains of B2 monomers are critical for dimerization. Virology 432:296-305.

Shiboleth, Y. M., Haronsky, E., Leibman, D., Arazi, T., Wassenegger, M., Whitham, S. A., Gaba, V., and Gal-On, A. 2007. The conserved FRNK box in HC-Pro, a plant viral suppressor of gene silencing, is required for small RNA binding and mediates symptom development. J. Virol. 81: 13135-13148.

Shockey, M. W., Gardner, C. O., Jr., Melcher, U., and Essenberg, R. C. 1980. Polypeptides associated with inclusion bodies from leaves of turnip infected with cauliflower mosaic virus. Virology 105:575-581.

Storms, M. M., Kormelink, R., Peters, D., Van Lent, J. W., and Goldbach, R. W. 1995. The nonstructural NSm protein of tomato spotted wilt virus induces tubular structures in plant and insect cells. Virology 214: 485-493.

Sun, L., Andika, I. B., Kondo, H., and Chen, J. 2013. Identification of the amino acid residues and domains in the cysteine-rich protein of Chinese wheat mosaic virus that are important for RNA silencing suppression and subcellular localization. Mol. Plant Pathol. 14:265-278.
Takeda, A., Sugiyama, K., Nagano, H., Mori, M., Kaido, M., Mise, K., Tsuda, S., and Okuno, T. 2002. Identification of a novel RNA silencing suppressor, NSs protein of Tomato spotted wilt virus. FEBS Lett. 532: 75-79.

Takeda, A., Tsukuda, M., Mizumoto, H., Okamoto, K., Kaido, M., Mise, K., and Okuno, T. 2005. A plant RNA virus suppresses RNA silencing through viral RNA replication. EMBO J. 24:3147-3157.

Valli, A., Dujovny, G., and García, J. A. 2008. Protease activity, self interaction, and small interfering RNA binding of the silencing suppressor p1b from Cucumber vein yellowing ipomovirus. J. Virol. 82:974-986.

Vargason, J. M., Szittya, G., Burgyán, J., and Hall, T. M. 2003. Size selective recognition of siRNA by an RNA silencing suppressor. Cell 115:799-811.

Widana Gamage, S. M. K., and Dietzgen, R. G. 2017. Intracellular localization, interactions and functions of capsicum chlorosis virus proteins. Front. Microbiol. 8:612.

Wu, H. W., Lin, S. S., Chen, K. C., Yeh, S. D., and Chua, N. H. 2010. Discriminating mutations of HC-Pro of Zucchini yellow mosaic virus with differential effects on small RNA pathways involved in viral pathogenicity and symptom development. Mol. Plant-Microbe Interact. 23:17-28.

Wu, J., Li, J., Mao, X., Wang, W., Cheng, Z., Zhou, Y., Zhou, X., and Tao, X. 2013. Viroplasm protein P9-1 of Rice black-streaked dwarf virus preferentially binds to single-stranded RNA in its octamer form, and the central interior structure formed by this octamer constitutes the major RNA binding site. J. Virol. 87:12885-12899.

Xie, Z., Johansen, L. K., Gustafson, A. M., Kasschau, K. D., Lellis, A. D., Zilberman, D., Jacobsen, S. E., and Carrington, J. C. 2004. Genetic and functional diversification of small RNA pathways in plants. PLoS Biol. 2:e104.

Xu, A., Zhao, Z., Chen, W., Zhang, H., Liao, Q., Chen, J., Carr, J. P., and $\mathrm{Du}, \mathrm{Z}$. 2013. Self-interaction of the cucumber mosaic virus $2 \mathrm{~b}$ protein plays a vital role in the suppression of RNA silencing and the induction of viral symptoms. Mol. Plant Pathol. 14:803-812.

Yang, X., Baliji, S., Buchmann, R. C., Wang, H., Lindbo, J. A., Sunter, G., and Bisaro, D. M. 2007. Functional modulation of the geminivirus AL2 transcription factor and silencing suppressor by self-interaction. J. Virol. 81:11972-11981.

Yang, X., Xie, Y., Raja, P., Li, S., Wolf, J. N., Shen, Q., Bisaro, D. M., and Zhou, X. 2011. Suppression of methylation-mediated transcriptional gene silencing by $\beta \mathrm{C} 1-\mathrm{SAHH}$ protein interaction during geminivirusbetasatellite infection. PLoS Pathog. 7:e1002329.

Ye, K., Malinina, L., and Patel, D. J. 2003. Recognition of small interfering RNA by a viral suppressor of RNA silencing. Nature 426:874-878.

Ye, K., and Patel, D. J. 2005. RNA silencing suppressor p21 of beet yellows virus forms an RNA binding octameric ring structure. Structure 13: 1375-1384.

Yeh, S. D., and Chang, T. F. 1995. Nucleotide sequence of the $\mathrm{N}$ gene of Watermelon silver mottle virus, a proposed new member of the genus Tospovirus. Phytopathology 85:58-64.

Yeh, S. D., Lin, Y. C., Cheng, Y. H., Jih, C. L., Chen, M. J., and Chen, C. C. 1992. Identification of tomato spotted wilt-like virus infecting watermelon in Taiwan. Plant Dis. 76:835-840.

Yeh, S. D., Sun, I. J., Ho, H. M., and Chang, T. F. 1996. Molecular cloning and nucleotide sequence analysis of the S RNA of watermelon silver mottle tospovirus. Acta Hortic.: 244-260.

You, B. J., Chiang, C. H., Chen, L. F., Su, W. C., and Yeh, S. D. 2005. Engineered mild strains of Papaya ringspot virus for broader cross protection in cucurbits. Phytopathology 95:533-540.

Zhai, Y., Bag, S., Mitter, N., Turina, M., and Pappu, H. R. 2014. Mutational analysis of two highly conserved motifs in the silencing suppressor encoded by tomato spotted wilt virus (genus Tospovirus, family Bunyaviridae). Arch. Virol. 159:1499-1504.

Zhang, X., Yuan, Y. R., Pei, Y., Lin, S. S., Tuschl, T., Patel, D. J., and Chua, N. H. 2006. Cucumber mosaic virus-encoded $2 \mathrm{~b}$ suppressor inhibits Arabidopsis Argonaute1 cleavage activity to counter plant defense. Genes Dev. 20:3255-3268. 